\title{
Bargaining in the Shadow of the Community: Neighborly Dispute Resolution in Beijing Hutongs
}

\author{
HAINI GUO \& BRADLEY KLEIN*
}

I. INTRODUCTION 826

II. BACKGROUND ON THE HUTONG RESIDENTIAL ENVIRONMENT ... 829

A. From "Siheyuan" to "Dazayuan": A Brief History of Beijing Hutongs

B. Social and Spatial Intimacy: Hutongs as Residential Environments Today

C. Standing at the Crossroads: The Importance of the Timing of This Study

IV. THE THREE-TIERED HUTONG DISPUTE RESOLUTION REGIME

A. Institutional Scaling and the Basic Menu of Dispute Resolution Options

B. Non-Legalistic Public Authorities I: The Residents' Committees ("Juwei Hui")

C. Non-Legalistic Public Authorities II: Neighborhood Police ("Pianer Jing")

V. THE PRIMACY OF NORMS IN HUTONG DISPUTE RESOLUTION

VI. WHY NORMS?: COST-BENEFIT ANALYSIS AND THE CHOICE BETWEEN NORMS AND LAW

A. Time, Money, Uncertainty, and Social Disruption: The Many

Costs of Formal Legal Solutions

B. Where Social Ties End: The Domain of Formal Rules (and Law) in Hutong Life

C. Predictability, Best Practices, and Socially Constructive "Voice":

The Advantages of Mediated Solutions 885

VII. MAKING MEDIATED SOLUTIONS STICK: REPRISALS, STATUS, SHAME, GIFTS, AND OTHER INFORMAL SOCIAL ENFORCEMENT MECHANISMS

* Both authors received their J.D.s from the Yale Law School in 2004. We would like to extend our heartfelt thanks to Paul Gewirtz, Jamie Horsley, Jonathan Hecht, Suzanne Yueh, and all the other people at the Yale China Law Center who made this project possible. We would also like to acknowledge Liang Lihua, Liu Xiaoyan, Zhuang Shuo, Wu Bo, and the many other friends who provided us with invaluable assistance in our field research-we could not have completed this project without you. Finally, a special note of thanks is also due to Professor Robert Ellickson, whose guidance and input helped both authors immeasurably. 


\section{A LOOK AHEAD: THE IMPLICATIONS OF LEGAL REFORM, URBAN DEVELOPMENT, AND SOCIAL CHANGE}

IX. SUMMARY 907

\section{INTRODUCTION}

For more than a decade now, scholars from several academic disciplines have been preoccupied with examining the role of informal social norms-as contrasted with formal law-in coordinating social behavior, determining individual entitlements, and guiding dispute resolution efforts. It has been found that extralegal norms determine individual entitlements in cattletrespass disputes between neighbors in rural California ranching communities, ${ }^{1}$ govern contractual relationships in the New York diamond industry, ${ }^{2}$ structure individual obligations under collective pollination regimes among Washington orchard owners, ${ }^{3}$ settle disputes over karaoke noise pollution, ${ }^{4}$ and guide the operations of Japan's National Sumo Association. ${ }^{5}$ Other studies have suggested that extralegal norms are also instrumental to groundwater distribution regimes, ${ }^{6}$ the exercise of voting rights, ${ }^{7}$ conflict management between neighbors in urban America, ${ }^{8}$ the prevalence of smoking and certain sexual behaviors, ${ }^{9}$ and other macro-level socio-political phenomena. Most of these studies have confirmed the relevance-indeed the primacy-of informal social norms in determining

1 See generally ROBERT C. ElLICKSON, ORDER WITHOUT LAW: HOW NEIGHBORS SETTLE DiSPUTES (1991) (using cattlemen in Shasta County, California, to illustrate that members of a close-knit group can develop informal norms that are utilitarian).

${ }^{2}$ Lisa Bernstein, Opting Out of the Legal System: Extralegal Contractual Relations in the Diamond Industry, 21 J. LEGAL STUD. 115, 130-43 (1992).

${ }^{3}$ Steven N.S. Cheung, The Fable of the Bees: An Economic Investigation, 16 J.L. \& ECON. 11, 30 (1973).

${ }^{4}$ Mark D. West, The Resolution of Karaoke Disputes: The Calculus of Institutions and Social Capital, 28 J. JAPANESE STUD. 301, 303-06 (2002).

5 Mark D. West, Legal Rules and Social Norms in Jápan's Secret World of Sumo, 26 J. LEGAL STUD. 165, 200-01 (1997).

6 Elinor Ostrom et al., Rules, Games, AND COMMON POOL RESOURCES 283-300 (1994).

${ }^{7}$ Richard L. Hasen, Voting Without Law?, 144 U. PA. L. REV. 2135, 2151-64 (1996).

${ }^{8}$ Sally Engle Merry, Going to Court: Strategies of Dispute Management in an American Urban Neighborhood, 13 LAW \& SoC'Y REV. 891, 899-908 (1979).

9 Cass R. Sunstein, Social Norms and Social Roles, 96 CoLUM. L. REV. 903, 930-47 (1996). 
individual entitlements and resolving disputes. Yet all of these prior pieces of scholarship have focused on disputes in societies characterized by a developed economy, a more or less robust, independent set of legal institutions, and a liberal democratic political system.

This study aims at adding a needed perspective to the existing literature by examining dispute resolution practices in a far different environment: the traditional neighborhoods ${ }^{10}$ of urban China. Unlike the environments examined in prior studies, Hutong neighborhoods are economically underdeveloped and subject to an institutionally deficient legal system, a non-democratic political regime, and a distinctly illiberal post-war cultural experience. The extent which dispute resolution practices in ancient Beijing Hutong neighborhoods track those prevalent in the modern Western world has great implications for the law and society literature of the last decade.

Are the norm-based systems documented over the last ten years a truly universal human phenomenon, or are they a more distinct product of practices and intuitions unique to developed liberal market societies? Are there unique practices or institutional arrangements in radically dissimilar cultural settings that can help enrich-and place in proper perspective-our understanding of more familiar dispute resolution mechanisms? Are there valuable lessons that we in Western academia can learn?

In fact, our research did reveal that residents of Beijing Hutongs rely primarily on informal social norms in determining individual entitlements and resolving disputes among themselves. Private bargaining between individuals according to community social norms is the default option for residents who have grievances against their neighbors. Recourse to formal legal channels is viewed as too costly, socially disruptive, and unpredictable to be an efficient option in all but the most serious disputes. In these respects, our findings corroborate the general thrust of recent law and society scholarship on dispute resolution in more developed countries. The main point of divergence in general orientation is the Hutong residents' view of formal legal institutions as fundamentally unpredictable and untrustworthy, as opposed to simply too expensive. This finding derives directly from the underdeveloped nature of the Chinese legal system and thus may be common to dispute resolution regimes across the developing world.

Yet, even within this familiar norm-based orientation, novelties emerge as Hutong communities use some unique institutional arrangements to manage norm-based dispute resolution. When disputes between neighbors prove intractable, Hutong residents engage in a set of unique, middle

${ }^{10}$ See infra discussion Parts II.A, II.B (providing a full description of Hutongs as residential environments). 
institutions we term "non-legalistic public authorities." Comprised of the local Residents' Committees and specialized Neighborhood Police, these institutions lie somewhere between the domains of formal law and informal social norms. They are institutions expressly tied to the community that act as neutral mediators for Hutong residents. They are commissioned by the Beijing municipal government and they receive salaries from public funds, but they do not apply formal legal rules in mediating disputes and they have no coercive or punitive powers. Instead, they act as specialized custodians of community social norms, resolving disputes as those norms dictate, and relying on the community's collective informal sanctioning of intransigents to enforce their mediated solutions.

Through these institutions, Hutong residents benefit from the cost, flexibility, and convenience advantages of norm-based solutions while also securing some of the benefits of institutional specialization and standardization. While simultaneously providing some standardization, consistency; and predictability in the mediation process, these non-legalistic public authorities can articulate and refine community norms according to best practices and the changing social needs of the community. Such "expert" third parties also alleviate the difficulties of bilateral bargaining and reduce the likelihood of socially destructive norm-application by individual residents. They also bring standardization, consistency, and predictability to the mediation process. Thus, our results suggest that, while social norms are certainly the informal creation of the community, formal institutions can actually play a vital role in upholding and administering a norm-based social regime, often achieving results preferable to purely informal, decentralized modalities.

The solutions mediated by these non-legalistic public authorities are in turn enforced informally by the community through direct physical reprisals or group social punishments against norm-violators. In this process, residents' reputation and status within the community is a vital consideration, and many of the residents appear to be maximizing social status as much as economic efficiency in upholding norm-based dispute resolutions. This result implies that, at least for pre-market communities, social status may be just as important as material wealth in individual dispute resolution calculations.

At the very least, this study hopes to add an important missing data point to the accumulated law and society literature on dispute resolution mechanisms and the complex relationship between law and general social practice. Dispute resolution practices in developing countries and (postcommunist states in particular) deserve to be understood and incorporated into the literature. At its most ambitious, this project seeks to inject some fresh insight into the received wisdom of the field, uncover novel 
institutional arrangements, raise new questions, and add some important new elements to the overall picture painted by the scholarship of the last decade. It also may provide some valuable lessons for other communities facing the difficult transition from more traditional ways of life to technological modernity.

This Article is comprised of seven main Parts. The first Part will discuss the Hutong neighborhoods themselves, both as historical residential institutions and as modern living environments in Beijing today. The second Part will briefly describe our research methods. The third Part will review the basic, three-tiered dispute resolution regime available to Hutong residents, with special emphasis on two unique institutions - termed "non-legalistic public authorities"- that specialize in mediating disputes between neighbors: the Residents' Committees ("juwei hui") and the Neighborhood Police branches ("pianer jing"). The fourth and fifth Parts will discuss our research findings in some depth, including which dispute resolution mechanisms Hutong residents prefer for different recurring dispute types and why residents prefer certain norm-based dispute resolution mechanisms (and associated informal institutional arrangements) over more formalized lawbased options. The sixth Part will address the enforcement of norm-based dispute resolutions in Hutong neighborhoods, touching upon the role of private reprisals, public shame, and internalized values in making normbased dispute resolutions stick. The final Part will conclude with a brief assessment of the future of the Hutong dispute resolution regime amid the deep social and economic changes underway in present-day urban China.

\section{BACKGROUND ON THE HUTONG RESIDENTIAL ENVIRONMENT}

\section{A. From "Siheyuan" to "Dazayuan": A Brief History of Beijing Hutongs}

Beijing's numerous Hutongs have served as long-standing residential institutions for generations. The word "Hutong" refers to the lanes or alleyways that connect the traditional living quarters of Beijing residents, known as "siheyuan," or quadrangles. While linguists still argue about the exact meaning of the term "Hutong," many believe that it originated from the Mongolian word for "huddug" which means "a well to draw water from."11

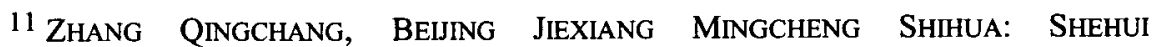
YUYANXUEDE ZaITANSHUO [HISTORY OF THE NAMES OF BEIJING'S LANES AND ALLEYS: SOCIO-LINGUISTIC RE-EXPLORATION] 462 (1997). There are scholarly debates about the original meaning and evolution of the term "Hutong." See id. at 460-68. One explanation 
This Mongolian term was adopted to describe these lanes and alleys because Beijing was largely expanded as a capital city by the Mongolian Yuan dynasty in China (1276-1368 A.D.). ${ }^{12}$ Beijing has served as the capital of the country since then, ${ }^{13}$ and, despite changes in governments, the basic structure of the city was kept largely intact until the early 1980 s, when the city began undergoing large-scale construction and modernization efforts. ${ }^{14}$

The complex urban honeycomb of Hutongs and quadrangles that grew out of the Yuan dynasty has remained an important residential environment in Beijing for centuries. Most of the Hutong neighborhoods that remain today were built in the Ming and Qing dynasties, though some can still be identified as from the earlier Yuan dynasty. ${ }^{15}$ Typically, Hutongs connect vast networks of "siheyuan" (or quadrangle) residences. The term "siheyuan" refers to the traditional-style Beijing courtyard house, each consisting of a rectangle courtyard surrounded by single-story tile-roofed houses on all four sides. The Hutongs themselves serve as passageways between rows of these

for the term "Hutong" is that the word originated from a Chinese word which means "fire lanes." The evidence for this explanation is that there was a specific rule as to the width of these alleys so they could serve as fire lanes during the Yuan dynasty. WONG LI, BEIJINGDE HUTONG [BEIJING'S HUTONG] 4 (1992). As the population of the capital grew with time, however, this rule could no longer be followed by mid-Yuan. Id.

12 In the year of 1271, Kubla Khan led his Mongolian army to conquer China and established the Yuan dynasty with its capital in Beijing, which literally means the Northern Capital. Id. at 152-75. Although this was not the first time that the city served as a capital, Beijing was redesigned and greatly expanded during this period of time with many Mongolians settling there. Id. Today, only a few sites in the city of Beijing can be traced back to the Yuan dynasty. Id. The Yuan design laid the foundation for the capital. $I d$. It is believed that the people who lived there built their houses around the wells and Hutongs were those narrow lanes leading to the wells. Id. When the next dynasty, the Ming Dynasty (1368-1644 A.D.), moved its capital to Beijing in 1403, it followed the Yuan design and kept the Hutong structure of the ordinary residences. See id.

13 The Ming first established their capital in Nanjing in 1368 and moved to Beijing in 1403. DANGDAI BEIJING JIANSHI [MODERN HISTORY OF BEIJING] 2-12 (Zhou Yixing ed., 1995). The next and the last dynasty, Qing (1644-1911 A.D.) also had its capital there. Id. With the exception of the Nationalist government, which moved its capital to Nanjing between 1929 and 1949, Beijing has been the capital city for the last eight centuries. Id.

14 See Pushpa Adhikari, Traditional Homes Bulldozed By Modernity, ASIA TIMES ONLINE, March 16, 1999, at http://www.atimes.com/china/AC16Ad01.html (last visited Mar. 11, 2005); Will Beijing's Hutongs Vanish?, TRAVEL CHINA WEEKLY NEWSPAPER, available at http://www.chinavista.com/travel/Hutong/enHutong.html.

15 One such example is the Zhuanta Hutong on the west side of the city. This Hutong was mentioned in Yuan dramas and was also the birthplace of a famous Yuan playwright. See WONG, supra note 11 , at 9. 
siheyuan households. The majority of Hutongs run straight from east to west, though some also run from north to south. This arrangement is due to the traditional Chinese architectural convention of having residential houses facing south in order to take in more sunshine and resist cold wind from the north. ${ }^{16}$ Though initially built in orderly, grid-like configurations, centuries of construction efforts have made today's Hutong neighborhoods a labyrinthine web of winding alleyways and densely-packed residential structures. ${ }^{17}$ While historical records show that in the Yuan dynasty all Hutongs were required to be nine-meters wide, today's Hutongs vary widely in length, width, shape, and spatial orientation, ranging from ten meters to forty centimeters in width, and 8,000 meters to ten meters in length, with some Hutongs winding through more than twenty turns. ${ }^{18}$ Today, the word "Hutong" commonly refers only to residential areas, while the term "street" is generally reserved for commercial or industrial areas.

Statistics show there were about 413 Hutongs in Yuan dynasty Beijing, about 1170 in the Ming dynasty, and roughly 3200 by the year of $1944 .{ }^{19} \mathrm{By}$ the mid-20th century, Hutongs had become not only a trademark of the capital city, but also the way people outside the capital referred to Beijing's residential quarters and its residents' traditional way of life. The three words old Beijing residents use most often to describe traditional Hutong living are stability, interconnection, and harmony among neighbors. ${ }^{20}$ In the past, the most privileged Beijing residents could afford to have their own selfcontained living quarters, while the majority of common Beijingers

16 There is also a traditional feng-shui principle to such an arrangement. Therefore, the family members in a single siheyuan courtyard house would always occupy the row of houses facing south as their main living quarters while using the houses on the other three sides to serve as study, kitchen, storage, or guest rooms.

17 WONG, supra note 11 , at 13.

${ }^{18}$ Id.

19 These numbers are estimates rather than accurate statistics. The author of Beijing's Hutongs has bemoaned the fact that it is almost impossible to get an accurate count of these Hutongs because many are overlapping and confusing as they extend over time. See id. at 11. The number of Hutongs hugely increased in the Qing dynasty. Id.

${ }^{20}$ Many scholars have written on this so-called subject of Hutong culture. See XU ChengBei, LaObeiJing: Xiangmo Minfeng [The Old BeiJing: THE Hutong Residents' Customs AND Culture] 33-42 (1999); YANG DONGPING, Chengshi JifENG [Culture AND SPIRIT OF BEIJING AND SHENGHAI] 176-82 (1994). The Hutong residents we interviewed also used these three words over and over again to describe their daily life to us. 
inevitably had numerous contacts with their neighbors. ${ }^{21}$ The sheer spatial proximity of neighboring siheyuan courtyards along common Hutong alleyways, combined with the frequent need for neighborly help and cooperation in daily life, made harmonious relationships among residents crucial. Traditional governance structures also drew people together through administrative measures by forming neighborhood associations, with each household taking turns to guard the neighborhood.22 In such closely connected neighborhoods of courtyards and Hutongs, local residents tended to stay in the same place for generations, forging deep social bonds with their neighbors and formulating a unique set of local norms and customs to order their relationships and social activities. Sharing common Hutong space and close social ties helped Hutong residents appreciate the importance of having a stable community upon which they could rely, especially during historically chaotic eras. ${ }^{23} \mathrm{~A}$ common saying captures the essence of this perception: "A neighbor close by is much better than a relative afar." 24

The need to have a stable and harmonious neighborhood became even more crucial after the Communist revolution of 1949. In response to the Revolution, more and more people began to share courtyards that formerly housed only single families. ${ }^{25}$ The collapse of the Qing dynasty in 1912 saw a large-scale change of ownership in many siheyuan houses, as the former Manchu banner families had to move out. ${ }^{26}$ Later, when the Communist

21 While a typical siheyuan consists of a single courtyard, with houses on all four sides, it is occupied by one single family. See generally WONG, supra note 11 . The more affluent families often had several such courtyards linked together to form a compound. Id. As of today, the biggest existing siheyuan compound in Beijing has six courtyards with hundreds of rooms and two gardens. Id. Such luxurious residential compounds belonged to the Qing princes and high-ranking ministers and later to the high-ranking Communist leaders. Id. These compounds have built-in wells and other facilities, which enabled the occupants to live a relatively isolated life compared to the other residents. Id.

22 Interview with Residents' Committee, Jianguomen Wai District (July 26, 2002) (notes on file with authors).

${ }^{23}$ Since the Yaun dynasty, especially in the last century, Beijing, like many other places in China, had to undergo one chaotic upheaval after another as different political and military forces came and went.

24 This is actually the most-often used expression by the Hutong residents when asked during our interviews how they viewed their relationships with their neighbors and why they believed that the disputes among them were best solved through negotiation and mediation rather than the more formal legal means. See, e.g., Interview with Residents' Committee, Jianguomen Wai District, supra note 22.

25 Id.

${ }^{26}$ The last Manchu emperor of the Qing dynasty abdicated in 1912. LIANG SHIQIU, LiANG SHIQIU WENJI [THE COLleCtEd WORKS OF LIANG SHIQIU] 87 (2004). The Manchu 
Party gained control of China in 1949, Beijing again experienced tremendous changes in its residential quarters. Formerly private housing space was redistributed to the broader masses, such that almost all the previously single-family courtyard houses came to be occupied by multiple familiesexcept those courtyards reserved for high-ranking Communist Party officials. ${ }^{27}$ The communist government gradually took over more and more privately-owned households and redistributed them to the homeless urban poor and those who had followed the new government to Beijing. ${ }^{28}$ Through political campaigns like the anti-rightists movements in 1957 and the Great Leap Forward in 1958, the communist regime managed to get rid of many perceived political enemies by sending them to remote rural areas. Into their former residences flooded many poor families who used to live in the outlying villages and now came back to work in the new manufacturing sector of the city.

Gradually, the traditional siheyuan courtyard was replaced by what Beijingers call "dazayuan," or "big chaotic (multi-family) courtyards." What distinguishes a traditional siheyuan from a dazayuan is not only that more families occupy the latter, but also that more buildings, like sheds used as kitchens, storage rooms, or even bedrooms, were constructed by these families in common courtyard areas. Residents in these multi-family courtyard residences were increasingly forced to expand their living quarters into traditional courtyard areas and compete with each other for common

banners who used to occupy the best houses in the inner city had gradually adopted a quite decadent lifestyle as they were guaranteed annual income from the government without any need to work. Id. This had caused serious anti-Manchu sentiment among the Han people in the 19th century. Id. With their subsidies gone now that their government had been replaced by a republic controlled by the Han, many Manchu families lost their livelihood and had to sell or rent out their houses to the richer Han people. Id. One consequence of this change was that several families often found that they had to share one siheyuan together instead of each occupying one as before. Id. Another consequence was that many former Manchu banner men, in a desperate search for new employment, became the first generation of professional policemen in China and one of their major functions was to serve as guardians and mediators of their former neighborhood areas. Id. Their familiarity with the traditional Hutong way of life and neighborhood norms greatly helped them perform this new role. Id.

${ }^{27}$ LiU Yida, Huangtian Houtu: Beijing Yan [The Royal Capital: Beijing's PERSPECTIVE] 128 (1998).

28 In the 1950s, the first group of private houses the government took over belonged to those who had followed the nationalist government to Taiwan and thus did not cause any major social stir. Then the government required those who had been categorized as capitalists to transfer to the government all of the houses they owned but did not personally occupy. See id. 
space. While poor urban residents had lived in such multi-family settings for a long time, it became a much more common phenomenon under the communist government after 1949.29

The 1950s and 1960s saw a huge increase in China's population, and this in turn created immense pressure upon housing space for people living in Beijing. ${ }^{30}$ The communist government, preoccupied with its political maneuverings and limited by its economic resources, was not able to provide more housing for the Beijing residents for about three decades. ${ }^{31}$ During the infamous Cultural Revolution (1966-1976) and the earthquake of 1976, more and more families were squeezed into existing Hutong neighborhoods. ${ }^{32}$ To accommodate burgeoning local populations, these families ingeniously expanded their living quarters, not only into common courtyard areas, but also into the Hutongs themselves, so that the Hutong alleyways became narrower and narrower as people built makeshift sheds along them. Former kitchens, which traditionally occupied the west side of a siheyuan quadrangle, were quickly converted into family homes. To accommodate this, people divided up the courtyard-usually equally among the households-and built their own small kitchens. Trees and flowers were sacrificed to make room for more essential living structures, common space became increasingly scarce, and the distance between neighboring houses decreased constantly. ${ }^{33}$

By the end of the 1970s, some architects sadly recognized that the traditional siheyuan had all but vanished as a residential building, replaced by the cluttered dazayuan, which consisted of random clusters of houses and shelters of different sizes and shapes, crowded with so many people that it was hard to find adequate space for almost anything. ${ }^{34}$ These changes made

29 These trends are discussed in general terms in WONG, supra note 11.

30 While we do not have accurate statistics due to the lack of official population surveys for the period between 1949 and 1982, the number provided by Beijing Population Association represents a good estimate. According to their statistics, the population of Beijing increased from 4.14 million in the year of 1949 to 8.4952 million in the year of 1979. BEIINGSHI BEIJINGSHI RENKOU TONGJ ZILIAO [STATISTICS ON BEIING's PoPUlation] (Beijing Population Association 1995); see also Data, U.N. Economic and Social Commission for Asia and the Pacific, at http://www.unescap.org (last visited Mar. 11, 2005).

31 According to official sources, urban residential construction stopped since the mid 1950s and did not start again until the early 1980s. See YANG, supra note 20, at 211-13.

32 Interview with Residents' Committee, Jianguomen Wai District, supra note 22.

33 These trends were discussed in several of our interviews. See, e.g., id.

34 YANG, supra note 20, at 220-21. There are a couple hundred traditional sihuyuan that have not been destroyed in Beijing, and they are now preserved as historical sites. Id. 
extensive daily interaction between neighbors inevitable, including daily negotiations over the need to allocate common space on an equitable basis. Within this context, harmony and cohesion within Hutong communities took on a new importance. As one resident summarized it, "The only way to survive in this kind of chaotic residential areas is to live with one another in harmony."35

When Deng Xiaoping initiated his reform plans for China in 1979, Beijing's housing situation presented a serious problem. ${ }^{36}$ By that time, about two-thirds of the Beijing's 8.5 million people lived in Hutong neighborhoods. ${ }^{37}$ To alleviate space constraints, many families started adding second floors to their courtyard buildings, and this caused several serious accidents. ${ }^{38}$ Fire lanes were occupied and traffic jams became worse as more shelters appeared along both sides of the already narrow Hutongs. ${ }^{39}$ Toward the end of 1979, the municipal government of Beijing declared such shelters illegal and ordered them to be removed. 40

In order to solve the housing crisis, the government started a large-scale construction program to build more high-rise apartment buildings. With the advancement of the economic reforms, however, Beijing soon faced a more fundamental structural change. The government began to demolish traditional Hutong residential neighborhoods in order to make room for the new, modern infrastructure which the city seemed to need to sustain its rapid economic growth. ${ }^{41}$ Various demolition projects have been initiated since the early 1980s, and many Hutongs have been flattened and replaced with modern plazas, department stores, office skyscrapers, and residential highrises. As of today, official statistics show that there are only about 850 Hutongs left in Beijing, and less than one-fourth of its 13.82 million people still live in these areas. ${ }^{42}$ In the Xicheng district alone, more than 260

35 Interview with Resident Group, Jianguomen Wai Hutong neighborhood (July 24, 2002) (notes on file with authors).

${ }^{36}$ An illustrative example is that the marriage age was greatly delayed due to a lack of housing. The average age for marriage was roughly extended by three years to 26 (for men). Meanwhile, a lot of married couples had to live separately for a few years before they could be assigned a room belonging to themselves. Id.

${ }^{37} \mathrm{Id}$.

${ }^{38} I d$.

${ }^{39} \mathrm{Id}$.

40 YANG, supra note 20, at 220-21.

41 Id. at 221.

42 Id. at 221; see also supra note 14. 
Hutongs have disappeared since the 1980s. ${ }^{43}$ Today, the Hutongs are vanishing fast as demolition projects proceed with increasing speed.

These housing reforms and Hutong demolition projects have brought significant demographic changes to the Hutong population, the most obvious being that today's Hutong residents are mostly comprised of low-income, poorly educated people. ${ }^{44}$ While the state assigned residential space to individuals through their direct employment units, ${ }^{45}$ the new reforms opened up channels for people to acquire new apartments. ${ }^{46}$ The new reform policies greatly benefited those equipped to participate in a competitive market economy, namely those who are young and well-educated and who are able to earn more money and move out of their Hutong residences. Poorly educated working-class people, however, lost much of the privilege and economic security they had enjoyed under the Mao regime, and they were unable to benefit from the new opportunities presented by marketization. In fact, the on-going reform of state-owned enterprises also means that many of these working class people are being laid off as their employment units are either closed or privatized, leaving them to face the perils and uncertainties of the market alone. With no way of procuring better housing themselves, many Hutong residents are forced to accept government cash compensation or relocation to government-assigned apartment buildings—often far from their old neighborhoods - as their existing neighborhoods are demolished. ${ }^{47}$

43 WONG, supra note 11 , at 195.

44 Accurate statistics as to the economic situations and income levels of the Hutong residents are extremely hard to find. From what we have gathered from our interviews and surveys, however, we have a good estimate. The average annual income of these Hutong residents appears to be significantly lower than the official number of RMB 39,000 (about $\$ 4,875$ ) for the year 2001 . The average annual income for Hutong residents actually probably ranges from $\mathrm{RMB} 12,000$ to 20,000 (about $\$ 1,500$ to $\$ 2,500$ ). For the official number, see BEIJING DAILY, June 17, 2002, at 1.

45 Under the Mao regime, almost all houses were owned by the state, and they were distributed to the residents through their own employment unit, such as a university or a factory. As long as one was formally employed by these state-owned units, he or she was entitled to be assigned at least a room to live in. The rent charged upon individuals for these assigned houses was only symbolic. This privilege, however, only belonged to urban residents. The huge costs of sustaining this housing system also made it almost impossible for the already faltering national economy to find resources to build more houses.

46 These channels include allowing individual residents to buy and lease from the state, or to put money together through their employment units to have new apartment buildings constructed.

47 To summarize, the first group to leave the crowded and chaotic Hutong dazayuan areas included those whose employment units that were able to provide better housing 
Such urban development projects are part of a broader government effort at urban housing reform. Over the last 20 years, the Chinese government has attempted to accelerate privatization of urban housing, and this has resulted in a property rights regime that is complex and constantly changing. In the Hutong areas, where we conducted our research, ownership rights in both land and residential structures are still mainly vested in the government. ${ }^{48}$ The majority of Hutong residents were assigned to their current living quarters by their work units ("danwei") before the 1980s, and they enjoyed occupancy rights in their residences in exchange for extraordinarily low rent. ${ }^{49}$ Only a small minority (we estimate less than $5 \%$ ) actually own their houses through inheritance, and, even in these cases, private ownership rights only extend to the houses themselves, as all land in China-including land under privately-owned houses-is owned by the government. ${ }^{50}$ Additionally, private homeowners cannot always legally sell their houses, especially if other individuals enjoy countervailing occupancy rights through government

and those who could afford to gain access to new apartments through either connection or money. The rest of the residents who can only depend upon government demolition projects and compensation plans are often subject to huge governmental pressures. Initially, the new apartments the government used to switch with their traditional houses were often located in newly-developed areas farther removed from the city proper and the compensation they got was often inadequate. In recent years, however, more and more residents are resorting to legal means to protect their rights against the government taking. This information was provided to us by a Qinghua Law School Professor, but we were asked to keep them confidential. See also Interview with Residents' Committee, Jianguomen Wai District, supra note 22; Interview with Qianmmen President (unknown date) (notes on file with authors).

48 As recently as 1997 , "nearly $80 \%$ of the urban population was living in stateowned housing." Eddie Chi Man Hui \& Francis Kwan Wah Wong, Housing Reform in Guangzhou and Shenzhen, China, 11 REV. OF URB. AND REGIONAL DEV. STUD. 141, 141 (1999). See generally Jieming Zhu, Changing Land Policy and Its Impact on Local Growth: The Experience of the Shenzhen Special Economic Zone, China, in the 1980s, 31 URB. STUD. 1611 (1994) (discussing the new land policy in the Shenzhen Special Economic Zone and the implications for the populace of that area).

${ }^{49}$ For instance, the actual rents in the mid-1980s still comprised barely $1 \%$ of urban household expenditures and $6.5 \%$ of the full-cost rent. Zhong Yi Tong \& R. Allen Hays, The Transformation of the Urban Housing System in China, 31 URB. AFF. REV. 625, 634 36 (1996). The reason for collecting such low rents on state-owned housing was both to support the socialist conception of housing as a welfare good, and to enable the low wages which formed the foundation of the urban state labor-management regime. Id.

${ }^{50}$ See generally Ok-kwok Lai, Governance and the Housing Question in a Transitional Economy, the Political Economy of Housing Policy in China Reconsidered, 22 HABITAT INT'L 231, 234 (1998) (discussing reforms by the Chinese Government in housing policy). 
assignments. ${ }^{51}$ Thus, most Hutong residents are painfully aware that property rights in urban housing are still uncertain, hard to untangle, and often subject to arbitrary negation by the government, work units, and even individuals in valid possession of the property. As might be expected, the precarious nature of housing ownership rights generally deters residents from seeking ownership stakes in the houses they inhabit, and this contributes to their general sense of economic insecurity and disadvantage.

All these recent changes have given the term "Hutong" a somewhat negative and derogatory connotation both economically and culturally, although the term also conveys a feeling of nostalgia. To say somebody is from a Hutong often implies a lack of good education and good taste; the Hutong way of life is generally considered outdated and not in keeping with Beijing's more modernized lifestyle today. ${ }^{52}$ Fortunately, the Beijing Institute of City Planning and Design has listed nineteen Hutong and "siheyuan" quadrangles as historical and cultural protection sites to be exempted from demolition under future urban development programs. ${ }^{53}$

\section{B. Social and Spatial Intimacy: Hutongs as Residential Environments Today}

Upon first glimpse, the Hutongs in Beijing might appear all the same with gray walls and worn bricks and a few trees or plants lining one side. Traditional-looking gates leading to individual courtyards dot and decorate both sides of the narrow alleyways. Toward one end of a Hutong, one can usually find a public water fountain with a cement sink. On the other end are the public toilets. Against the walls on both sides of the alleyways, one finds

51 This is to say nothing of the makeshift structures built by residents in common courtyard areas. These structures evidently are not even protected by a private right of occupancy, as they are not officially registered with the central government. Legally speaking, these structures do not exist.

52 The younger generation despises the fact that the close proximity of Hutong households offers no privacy: The younger generation also considers modern facilities such as private bathrooms a necessity. Interview with Resident Group, Jianguomen Wai Hutong neighborhood, supra note 35 . Through our interviews, we also found out that about one-third of our subjects had been laid off or forced to retire from a former stateowned enterprise and are now either doing random jobs or searching for new employment. The majority of those who talked with us do not have a college education.

53143 BEIJING MUNICIPAL GovernMENT ARChIVES 72 (2001). These 19 preservation sites are those Hutongs and "siheyuans" that have maintained their traditional features without being occupied by multi-families and transformed into "dazayuan" under the communist regime. 
numerous bicycles and occasionally a crude brick and cement shed that was built in earlier years. On a quiet early summer afternoon, there are usually few people out in the Hutongs, often only retirees and young children. They are usually engaged in their own activities while enjoying the sunshine, a resource that has become very scarce inside their own living quarters due to the overcrowding of makeshift buildings in common courtyard areas. Toward evening, the Hutongs become much more lively as residents come back home from work. Many actually take their dinners outside to eat together with their neighbors, comparing and sharing each house's special culinary recipes. When it gets dark, more people come out into the Hutongs to chat, play chess or mah jong, eat watermelon, or watch small televisions, since their own bedrooms, lacking air-conditioning and good ventilation systems, are usually too hot to stay inside.

This is a familiar scene in almost any Beijing Hutong on a summer night, and many residents facing demolition of their residential quarters emotionally refer to this kind of communal lifestyle as a major reason why it is hard for them to give up what they know is, materialistically speaking, a rather shabby living environment. "Hutongs," said the residents, "are a happy kind of place where you enjoy a lot of interpersonal communication and sharing, despite our poverty and lack of space." 54

It is true that poverty and lack of space are undeniably characteristics of Hutong areas today. The Hutongs themselves are often badly in need of repairs with their narrow streets full of pits and holes which become muddy on a rainy day. The courtyard households vary in size but are uniformly overcrowded. A typical courtyard houses at least four families today, with an average of roughly 20 people sharing about 15 rooms on the four sides of the courtyard. The courtyard is no longer an open space, but rather a cluster of ugly sheds which function as kitchens, storage rooms, and even bedrooms. To get into one's own house, a resident must carefully navigate a labyrinthine maze of small buildings and bicycles. ${ }^{55}$ These families share one

54 Interview with Resident Group, Jianguomen Wai Hutong neighborhood, supra, note 35 . These sentiments actually echo the scholarship of Jane Jacobs and others, who have recognized the distinction between material wealth (physical capital) and overall community health and vitality (social capital) in American cities. Jacobs has decried the negative impact of urban development programs on the social health of American city neighborhoods. See JANE JACOBS, THE DEATH AND LIFE OF GREAT AMERICAN CITIES 325 (1961); see also WONG, supra note 11, at 192.

55 This is a description of one of the poorest and most crowded quadrangle courtyards we saw during our interviews. While most of the courtyard buildings we visited could boast a little more open space and wider passages leading to each individual house than this one, they all share the same characteristic of having a bunch of makeshift 
common entrance gate that opens onto the nearest Hutong. The gates are usually aesthetically appealing, bearing traditional Chinese architectural designs and decorations while functioning as a protective barrier against outsiders.

Sharing a single entrance gate also creates a feeling of sharing one common inner world among the families. ${ }^{56}$ Hutong residents tend to identify two communities in which they live: (1) the inner community of those families who share one courtyard, and (2) the outer community of residents from the courtyards located along the same Hutong. ${ }^{57}$ Although these two communities often overlap, residents do see them as distinct, and, socially speaking, they are most strongly aligned with those neighbors who live in their courtyard..$^{58}$ The social and spatial context of the Hutong residential neighborhoods thus presents inhabitants both opportunities for frequent friction and disputes, and the potential to build large stores of critical social capital. While neighborly disputes vary, they often involve the limited common areas in the courtyards. ${ }^{59}$ Different sorts of noise and odor nuisances have long become an inevitable part of life for Hutong residents, ${ }^{60}$ and limited common space is often subject to conflicting ownership claims

sheds built by individual households in the formerly common courtyard. This observation came from our visits to the following five Hutong areas during the summer of 2002: Jianguomenwai. Hutong, Yabaolu Hutong, Liulichang Hutong, Qianmen Hutong, and Houhai Hutong. Although we are only discussing the characteristics of these five areas, they are quite representative of the Hutongs left in Beijing today.

56 A caveat we need to make here is that the single families that used to occupy such siheyuan buildings often included several generations, especially for the middle-class people who could not afford to get an independent house for each grown-up child. In a sense, the family was composed of several "small families" that each occupied one side of the siheyuan. To outsiders, they were one single family, while inside they had to do a lot of intra-family and inter-generational negotiations and adjustments. According to some old residents with whom we talked, dealing within the family was even harder than dealing with neighbors without any blood relationships. The fact that many Hutong residents had this kind of previous experience, however, helped facilitate the multilateral adjustments among the different families now sharing one siheyuan. Interview with Resident Group, Jianguomen Wai Hutong neighborhood, supra note 35.

57 Id.

58 Id, see also LIANG, supra note 26 , at 131.

59 For discussion of typical disputes, see infra Part V.

60 This issue will be further discussed infra Part V. One nuisance that used to present a serious problem before the 1970 s was smoke from burning coal for cooking and heating - the city finally sent gas to these Hutong houses in the late 1970s and early 1980s. Interview with Resident Group, Jianguomen Wai Hutong neighborhood, supra note 35 . The Hutong residents really appreciate this improvement. Id. Storing a huge amount of coal for the winter also made the courtyards more unbearable spatially. $I d$. 
(or proposed uses) among families. ${ }^{61}$ The fact that the families sharing the same courtyard often have only one wall separating them from one another leaves families exposed to public scrutiny. Knowledge of neighbors' personal lives provides fertile soil for gossip and minor disputes. ${ }^{62}$ One resident asked us rhetorically:

As the Chinese proverb puts it, "Pots and pans inevitably collide with each other in every household." How can you expect people of different characters living so close to each other to have zero confrontations? But, we accept this as part of our life and we do not let them seriously disrupt our neighborly relationships, as that is not the right thing to do. ${ }^{63}$

The close physical proximity of the Hutong residences and the inevitably daily interactions among neighbors create a strong need for mutual dependence and reciprocal cooperation. ${ }^{64}$ Such bonding social capital has become an essential part of the Hutong way of life to the residents. This is of especially great value to lower-class working residents who have few outside resources, either economic or administrative, on which to rely. The political regimes under which the residents have lived have not been very efficient in providing a safety net. 65 Further, the harsh economic situation many residents face today renders the social capital invested in their immediate neighborhood communities even more important. Despite their frequent friction over mundane issues, residents have a strong sense of sharing both benefits and burdens with their neighbors. They look out for each other and

61 Our interviews show that these kind of disputes occur most often among Hutong residents. A typical example would be one family building their kitchen either slightly wider or taller than those of the neighboring families in the courtyard. Id. This taller shed could block sunlight from the other sheds and also cause more water to fall upon the neighboring roofs when it rains heavily. Id.

62 For discussion of typical disputes, see infra Part V.

63 This comment was made by Huang Yongyu, a 67-year-old resident who had lived in a Hutong house all her life and wished she could die there. Interview with Resident Group, Jianguomen Wai Hutong neighborhood, supra note 35.

64 For discussion of enforcement of mediated solutions, see infra Part VII.

65 The last three dynasties-Yuan, Ming, and Qing-were not able to have their ruling power penetrate down to the neighborhood level, and pretty much left the local residents to manage their own livelihood while relying upon the traditional Baojia system to police them. The communist regime tightened its control over every citizen politically and economically, and significantly limited the scope of urban residents' employment. Once the government was no longer able to provide sufficient employment opportunities in the 1980s without simultaneously establishing an effective social security mechanism, many Hutong residents found themselves left in the cold of the new economic reforms. 
depend upon each other in performing many basic tasks of everyday life, such as childrearing, housekeeping, and maintaining social order. The children in any given courtyard generally grow up together, often under the common care of the grandparents and parents of all the neighboring families. ${ }^{66}$ While the lack of distance and space deprives residents of their personal privacy, it also furnishes a formidable public supervision system that contributes to public safety and promotes mutual adjustment and cooperation. ${ }^{67}$ In short, the extensive interdependencies among the Hutong residents cause the residents to view responsibility-sharing as a part of life. One resident articulated this sentiment nicely during an interview:

While it might appear to you that our courtyard is too crowded and chaotic, maybe even poor and shabby, we enjoy living here because the neighbors help each other immensely when one encounters any kind of difficulty. For instance, two nights ago the Zhang family living on the west side of our courtyard found their grandmother suffering from a heart attack. Every family went out to help. The young men took turns carrying her to the nearby hospital, as it was hard to get a taxi or ambulance into our Hutong at three o'clock in the morning. While the Zhang family members stayed at the hospital for the last two days, the neighbors each cooked some food for them and sent the food to the hospital, while at the same time taking care of their 11-year-old kid. I wonder where else one can find such cooperation among neighbors. Certainly not in those new apartment buildings, where next-door neighbors might not even know each other. ${ }^{68}$

Indeed many of the residents who had spent their whole lives in Hutong areas saw many advantages to living in such a close-knit community: They do not have to lock their doors, as the neighbors watch out for each other; they have a safe neighborhood; working parents do not need to worry about their school-age kids, as the neighbors look after them; the sick and the elderly are looked after by neighbors when family members are away; people out working do not have to worry about their laundry being dried outside

${ }^{66}$ The residents who talked with us emphasized this bonding factor in dealing with their disputes. Interview with Resident Group, Jianguomen Wai Hutong neighborhood, supra note 35.

${ }^{67}$ In the course of our field research, we were often confronted by watchful residents when we knocked on an absent neighbor's door. The residents always wanted to know who we were and what we wanted. There is a strong sense that each household must help monitor and protect the security of neighboring families.

${ }^{68}$ This comment was made by Qin Jiangong, a 64-year-old Hutong resident at the Jianguomen Wai Hutong. Interview with Resident Group, Jianguomen Wai Hutong neighborhood, supra note 35 . 
when the weather changes; one's mail is always picked up on time; neighbors guard their common interests against outsiders; the Hutongs provide a lively environment for kids to play and for peddlers to sell their wares ${ }^{69}$; there are always people with whom to chat and exchange gossip, which allows residents to keep up with contemporary events both within and outside the neighborhood; and there are always neighbors to share good food and tea with, which is especially important to older people whose social activities are severely limited. ${ }^{70}$ In summarizing this perspective, one resident put it this way: "There are both a lot of advantages and disadvantages to our living environment. There are a lot of costs and benefits to all ways of life, and we have to weigh these costs and benefits carefully to gain a balance in our approach to life." $" 71$ Poverty and interpersonal friction thus coexist with extensive cooperation and social bonding everyday in Hutong neighborhoods, providing a perfect environment for the study of extralegal dispute resolution methods.

\section{Standing at the Crossroads: The Importance of the Timing of This Study}

Beijing Hutongs are disappearing fast. While there are still about 900 Hutongs left, most of these have big white circles on their gray walls, with

69 The dense population living in these courtyard clusters attracts many peddlers. ZHANG, supra note 11 , at 379 . This was especially true during the earlier decades before the current market economy was developed. Id. From morning until night, peddlers selling different daily necessities and providing basic maintenance services toured these residential areas, rendering the life of the residents physically convenient. Id. While this aspect of Hutong life is disappearing nowadays due to the establishment of more supermarkets, many older generation residents have a deep nostalgia for it. See id.

${ }^{70}$ Interview with Resident Group, Jianguomen Wai Hutong neighborhood, supra note 35 . When we were visiting this Hutong neighborhood, we ran into Mr. Chen Lifa, a former resident who had moved to a new apartment building about ten miles away. $\mathrm{He}$ told us he missed his life and his neighbors in his former Hutong so much that he bought a month bus pass in order to come back everyday. When asked what was so appealing about the Hutong life, he sighed: "I feel so lonely in my new apartment though I get to enjoy all the modern facilities like a gas stove, a central heating system, and a private bathroom. I just miss the friendly environment of the Hutong where everybody knows about each other." Id. He then more or less listed the comments we discuss here. When asked whether he wanted to move back he said, "I wish I could combine both the material aspects of my new apartment with the Hutong human relationship and atmosphere." Id.

71 This comment was made by He Lianrong, a Hutong resident and a neighborhood committee worker. Interview with Residents' Committee, Jianguomen Wai District, supra note 22 . 
the Chinese character for demolition in them. ${ }^{72}$ These circles clearly symbolize to those passing by that yet another Hutong neighborhood will be flattened by bulldozers in the near future. To those living in these Hutongs, however, the white circles symbolize the future destruction of a way of life and the denial of an important element in Beijing's history. While many people in China today do think that these residential areas should be preserved as historical sites, the traditional Hutong way of life still appears to be out of tune with the rapid modernization efforts underway in Beijing. The younger generation in particular aspires to a more Western style of living, seeking the increased freedom, independence, and privacy afforded by selfcontained apartments. However, the many contradictions associated with modernization give some a sense of nostalgia for the close-knit communities of Hutong life. Many residents living in new apartments say that they often feel isolated and alienated from their neighbors. While they still feel the need to depend upon a strong social network, the apartment-dwellers find this network missing in their new living environment. ${ }^{73}$ This is one reason that both local governments and residents of new apartment buildings have initiated "community-building" programs in recent years. ${ }^{74}$

This study seeks to capture one important aspect of the disappearing Hutong way of life in Beijing: the Hutong residents' dispute resolution regime, which includes the relationship between traditional social practices and formal law within this regime. This study, we believe; promises not only to contribute to a better understanding of this specific traditional dispute resolution regime, but might also provide important lessons for other communities - in China and elsewhere - facing the cultural strains of rapid modernization and the complex task of remedial "community-building." The timing of this study is important, as we have managed to interview individuals whose neighborhoods are facing imminent demolition. Standing at the crossroads of tradition and modernity, these residents have provided us with their unique insights in considering and comparing two distinctive ways of life.

\section{RESEARCH METHODS}

We pursued our research primarily through face-to-face interviews with Hutong residents, Residents' Committee mediators, and Neighborhood Police Officers in the summer of 2002. In all, we conducted interviews with

72 See Adhikari, supra note 14; Will Beijing's Hutongs Vanish?, supra note 14.

73 See supra text accompanying note 70.

74 This campaign continues in Beijing. See WONG, supra note 11, at 192. 
65 residents of the Hou Hai, Jianguomen Wai, Liu Li Chang, Yabao Lu, Taiping Jie, and Qianmen Hutong areas of Beijing. We met with eight Residents' Committee mediators from the Jianguomen Wai and Yabao Lu Hutong neighborhoods and examined their records of resident disputes and mediation activities covering the time period from May 2001 to May 2002.75 We also accompanied a Neighborhood Police Officer on a full day of rounds in a Hutong neighborhood and witnessed his activities firsthand. ${ }^{76}$

The neighborhoods we visited collectively encompass both historic, well-touristed Hutongs designated for governmental preservation as well as less famous areas targeted for demolition. Each resident interview involved a fairly in-depth discussion, generally ranging from half an hour to two hours in length. Some of the interviews were conducted in groups, while others were done on an individual basis. Friends in Beijing helped us arrange interviews with relatives or friends living in Hutongs, and these interviews tended to be the longest and most comprehensive. ${ }^{77}$ Other interviews were with residents chosen at random as we visited these neighborhoods repeatedly over several months. ${ }^{78}$ Our interviewees included residents older than 80 and as young as 25 . Some had lived in their current residence less than one year, while others had lived in the same Hutong 50 years or more. One resident reported that his family had lived in the same Hutong for six generations. ${ }^{79} \mathrm{We}$ interviewed both men and women, literate and illiterate, employed and unemployed. Though most residents evinced a willingness to meet with us - some even invited us into their homes for food or drink-our results may overrepresent the helpful and outgoing. Some residents did refuse to participate in interviews because of suspicion or impatience. Many of our interviewees were illiterate and most were distrustful of formal written surveys (especially when administered by a foreigner). These difficulties

75 There were six volumes of records for this period, containing official accounts of 80 disputes between residents in the Jianguomen Wai Hutong neighborhood.

76 We took this unique research opportunity on August 27, 2002. The police officer we accompanied was uncomfortable with publicity and requested that we not report his name. Our findings from this excursion are discussed infra Part IV.C.

77 A special note of thanks is due to our wonderful friends in Beijing, without whose help this study would have been far more difficult and far less fruitful. In particular, Liu Xiaoyan, Liang Lihua, Zhuang Shuo, and $\mathrm{Wu}$ Bo provided invaluable assistance in arranging interviews, helping us orient ourselves in the Hutong neighborhoods, and providing occasional (but vital) translation assistance.

78 This includes interviews conducted during our observation of a Neighborhood Police officer's rounds in a Hutong area on August 27, 2002.

${ }^{79}$ Interviews with Residents, Hou Hai Hutong neighborhood (June 19-July 10 , 2002) (notes on file with authors). 
precluded the use of standardized written surveys for data-gathering, and we soon discovered that more informal, conversational approaches were far more fruitful modes of research. ${ }^{80}$ All interviews were conducted entirely in Mandarin.

In every interview we covered certain basic topics regarding the mechanics of available dispute resolution mechanisms and the methods used to resolve certain paradigmatic disputes types: property damage, physical fights, conflicts over use of common courtyard areas, noise complaints, allocation of water and electricity costs, etc. These common lines of questioning provided a certain continuity and coherence to the interview set, which allowed us to gain a consistent baseline understanding of the Hutong social world and its basic norms. Yet we also solicited more idiosyncratic, personalized accounts of memorable events. We always encouraged residents to elaborate on basic principles with illustrative stories. In this way, we tried to glean an understanding of the more general norms and principles that undergird Hutong social life, while simultaneously capturing the more colorful details of particular cases. Our interviews with the mediation "experts" in the Residents' Committee and our examination of the Residents' Committee mediation records also allowed us to cross-check resident accounts of the dispute resolution process, the norms that guide the process, and the typical outcomes of common dispute types.

Contrary to our initial apprehensions, Hutong dispute resolution mechanisms and the basic norms employed by residents proved strikingly uniform from neighborhood to neighborhood. Similarly, the more "expert" perspectives of the Residents' Committee mediators and the Neighborhood Police officers were highly consistent with the reports offered by individual residents. This overall consistency of results across disparate institutional and geographical contexts allows meaningful reference to a single Hutong dispute resolution "regime" encompassing a more or less coherent body of norms and institutions. It is to this regime that we now turn.

80 This methodological approach obviously lacks a certain amount of statistical rigor, but it is consistent with research methods used by other major scholars in the field. The study whose methodology is most similar to ours is Robert Ellickson's research on the resolution of cattle trespass disputes in Shasta County, California. See Robert C. Ellickson, Of Coase and Cattle: Dispute Resolution Among Neighbors in Shasta County, 38 STAN. L. REV. 623, 654-57 (1986). 


\section{The Three-TIEREd Hutong Dispute Resolution RegIME}

\section{A. Institutional Scaling and the Basic Menu of Dispute Resolution Options}

The Hutong dispute resolution system is organized into three fundamental tiers, or layers, each involving different institutional actors and implying distinct dispute resolution methods-an arrangement that can be termed institutional scaling. When a dispute arises, residents choose the tier that is best suited to their own needs and the contingencies of the specific dispute at hand, and they will change tactics and move between tiers of the system (or re-scale) as circumstances demand, especially if the dispute escalates or proves intractable. ${ }^{81}$ While our specific findings and research data will be discussed in the next section, it will be useful first to present the broad outlines of the Hutong dispute resolution regime and its three institutional tiers.

Simple informal neighbor-to-neighbor negotiations make up the first tier of the dispute resolution system, and indeed this is the default first option for residents who have grievances with their neighbors. ${ }^{82}$ Neighbor-to-neighbor negotiations often involve just the two parties involved in the dispute, but other nearby residents may participate, especially if they share common courtyard space or close social ties with the disputants. This mode of dispute resolution typically involves no formal rules whatsoever, so solutions are

81 The centrality of pragmatism in choosing dispute resolution mechanisms, as well as the availability of several different institutionalized dispute resolution options, echo the conclusions of other research in the field, particularly the recent scholarship of Mark D. West. See West, supra note 4, at 303 (reporting that Japanese citizens often decide to respond to karaoke noise pollution "through a bureaucratic pollution complaint resolution mechanism" rather than formal litigation based on consideration of the economic costs and social consequences of each alternative); West, supra note 5, at 200-01 (finding that Japan's National Sumo Association applies both formal association rules and informal social norms in resolving disputes and the choice between using rules or norms is based on a calculation of comparative efficiency).

82 The dispute resolution literature has created standardized terms to refer to the key elements of any dispute. "Grievance" refers to any complaint one individual has against another, "claim" refers to the aggrieved party's request for satisfaction or a certain solution recognizing the aggrieved party's entitlements, and a "dispute" emerges when such a claim is rejected. See Richard E. Miller \& Austin Sarat, Grievances, Claims, and Disputes: Assessing the Adversary Culture, 15 LAW \& SOC'Y REV. 525, 527 (19801981). While this standardized vocabulary has certainly proven useful in developing the dispute resolution literature, our use of these terms generally will reflect their colloquial meanings. 
customized and flexible, formulated by the mutual consent of the parties involved and tailored to their specific needs (often with input from concerned neighbors). Similarly, there is no role for coercive state power or public institutions in this first tier, nor is there any formalized procedure involvedan aggrieved resident will simply approach the offending neighbor and suggest they discuss the problem privately.

The second tier of the Hutong dispute resolution system involves more formal mediation of disputes by the local Neighborhood Residents' Committee ("juwei hui") 83 or special Neighborhood Police ("pianer

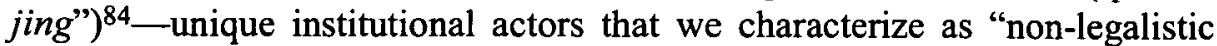
public authorities." The Residents' Committee is a small body directly elected each year by residents of the neighborhood to handle certain common tasks (such as garbage disposal and sanitation) and to oversee implementation of certain public policies (like the one-child policy). Committee members are typically elected from among the neighborhood's residents and tend to be respected members of the local community. They are paid salaries with public money, and at least one of them-typically one with a reputation for fairness and good judgment-will have a specialized mandate to mediate disputes between residents.

Residents involved in disputes with their neighbors can call the Residents' Committee and request that one of its members come and mediate ("tiao jie") the dispute. The Residents' Committee representative will then meet with the parties to the dispute, hear accounts of events from both the parties and any neighbors who may be able to shed light on disputed facts, and try to find common ground between the disputants. After such a meeting, the Residents' Committee representative will usually suggest that a certain solution is in the best interests of the community, and the disputants are urged to agree to it. Such resolutions usually impute some responsibility for the dispute on both parties as a way to demonstrate neutrality and allow all involved to save face..$^{85}$ The special Neighborhood Police play a similar role, but in an even more informal, ad hoc way. Neighborhood Police officers are members of a special branch of the municipal police assigned to patrol certain urban districts as general social "troubleshooters." Like the

${ }^{83}$ For a detailed discussion of the current role and historical evolution of the Juwei Hui as a dispute resolution institution, see our discussion infra Part IV.B.

${ }^{84}$ For a detailed discussion of the current role and historical evolution of Pianer Jing as a dispute resolution institution see our discussion infra Part IV.C.

85 The general position and function of the Residents' Committees is common knowledge in Beijing, and was gleaned through our formal interviews of friends in Beijing and out time spent living there. 
Residents' Committee, these special police are available to mediate disputes on request. However, more commonly, they make regular rounds through the neighborhood checking on residents, inquiring about recent residential conditions, and ensuring that emerging problems are contained. ${ }^{86}$

Though both the Residents' Committee and the Neighborhood Police are paid from the public fisc, they are distinctly non-legalistic institutions: They apply no formal rules in their mediation of local disputes, observe no set procedural requirements, and have no power to impose fines or other penalties on disputants. ${ }^{87}$ Instead, mediation leverages the existing social ties of the Residents' Committee members and the Neighborhood Police officers to the community, and is guided by shared principles of justice and common social understandings, giving the process both predictability and moral legitimacy in the eyes of residents. ${ }^{88}$ The resulting mediated solutions are thus much more flexible and customized than those imposed by formalistic legal institutions, but they are constrained somewhat by the shared principles of the community and the demands of preserving institutional legitimacydisputants do not enjoy the complete tabula rasa that characterizes informal neighbor-to-neighbor negotiations. Similarly, although no public coercive power is involved, resorting to this second tier involves intervention by a public authority acting in the name of the community, and this mobilizes

86 Id.

${ }^{87}$ All 65 residents we interviewed insisted that no pre-formulated rules were used by either institution in mediating disputes. In fact, many residents seemed mystified at our suggestion that formal legal rules could efficiently resolve local disputes. Even the Neighborhood Police, who theoretically have access to formal legal institutions and the coercive powers of the municipal government, typically did not refer to formal law when resolving problems between residents. Additionally, the Neighborhood Police do not have cars, are not armed, and are generally not authorized to use force against residents. The non-legalistic public authorities encountered in this study are evocative of the "pollution complaint counselors" who often handle karaoke noise pollution disputes in Japan. See West, supra note 4, at 303. Like the Hutong Residents' Committee and Neighborhood Police, Japan's specialized noise-complaint counselors appear to be effective at resolving private disputes despite their lack of formal coercive power. Id.

${ }^{88}$ The fact that members of the Residents' Committee are themselves residents of the community is undoubtedly crucial to the effectiveness of this institution. In her study of the role of norms in law enforcement, Tracey Meares has found that such "horizontal relationships" between legal authorities and common people are crucial to building trust in the law and fostering compliance with legal rules. Tracey L. Meares, Norms, Legitimacy and Law Enforcement, 79 OR. L. REV. 391, 393 (2000) ("[R]elationships between law enforcement authorities and the people matter more than consequences imposed by authorities to produce compliance with the law, in part because the desire of individuals to comply with the law is powerfully connected to their self-esteem."). 
social pressure and the exigencies of public shame to enforce mediated resolutions. ${ }^{89}$

The third tier of the Hutong dispute resolution regime is comprised of formal legal institutions such as municipal police, Public Security Bureau ("gongan ju") personnel, and the court system. These institutions bring the full weight of formal law, legal procedure, and the coercive power of the state to bear on disputes within their ambit. ${ }^{90}$ As a result, this third tier involves higher economic costs (including transaction costs), more social disruption, and a greater threat of punitive sanctions than the two lower tiers. Additionally, since formal legal rules-or policy decisions by political elites-are involved, solutions are not particularly flexible or customized.

The residents of Beijing Hutongs thus employ a three-tiered scalable dispute resolution regime, the different layers of which imply varying degrees of legalism, cost, flexibility, social disruption, and access to state power. This system is evocative of more general dispute resolution typologies in the literature, but with a unique and subtle twist. Most of the leading law and society scholarship presents a basic distinction between the world of "law" on the one hand and the world of informal "norms" on the other. Under the conventional view, "law" (or other formalized rules) and "norms" are seen as presenting disputants with two binary options for dispute resolution. 91

89 See infra Parts IV.B \& IV.C for discussion of the mechanics of mediation through these institutions and the enforcement of mediated solutions.

90 The role of law and procedure are measured relative to the other dispute resolution methods discussed here; no certain level of procedural rigor or commitment to the rule of law is implied.

91 The foundational work in this area is Robert C. Ellickson's Order Without Law: How Neighbors Settle Disputes, which originally proposed laws and norms as alternative bases for dispute resolution. See Ellickson, supra note 1. While the literature has certainly acknowledged that dynamic interaction occurs between formal laws and informal norms, with each affecting the development and application of the other, the basic treatment of formal law and informal norms as separate and distinct has persisted. See also Richard H. McAdams, The Origin, Development, and Regulation of Norms, 96 MiCH. L. REV. 338, 342-43 (1997); Meares, supra note 88, at 391-92; Cass R. Sunstein, On the Expressive Function of Law, 144 U. PA. L. REV. 2021, 2051-53 (1996); Sunstein, supra note 9 , at $907-10$. 
Laws and other written rules ${ }^{92}$ are commonly associated with official (usually legal) institutions, adherence to some form of legal procedure (with its associated costs), and the application of coercive public power to enforce resolutions. "Norms," on the other hand, are commonly associated not with formal institutions or procedures but with informal enforcement regimes relying on social sanctions..$^{93}$ Within the China Law literature, leading scholar Donald Clarke similarly distinguishes between "external" and "internal" dispute resolution mechanisms in Chinese society: "External" systems involve third-party mediators who have "no distinct relationship with the parties other than a specialized function as [a] dispute resolver" (such as formal legal institutions), while "internal systems" employ mediators who have authority "not because of [their] specialized function as dispute resolver[s] but because of some other distinct relationship with the parties" (such as family members).$^{94}$

Yet, the dispute resolution regime discussed here is not binary, but tripartite. The first tier-informal neighbor-to-neighbor negotiationcertainly fits the traditional view of norm-based dispute resolution, as well as the "internal" category of Clarke's typology. No formal procedures are used, no pre-formulated rules are applied, and no formal institutions are involved. Individuals participate in mediation or negotiation because of their social relationships with disputants or their physical proximity to the disputed events. The third-tier of the Hutong regime similarly fits the traditional conception of rule-based dispute resolution and Clarke's related "external" category. Lawyers, courts, and the police are summoned as neutral dispute resolution experts with no prior relationship with the disputants, official procedures are followed, formal laws are applied, and state power is enforced to produce an officially-mandated resolution.

The Hutong regime's second tier-that of the Residents' Committee and the Neighborhood Police-lies somewhere in between these two extremes. Both the Residents' Committee and the Neighborhood Police are institutional actors that specialize in dispute resolution, yet they also act as members of the disputants' community, enmeshed in the same web of social relationships as the disputants themselves. Indeed, as will be discussed, much of their

92 The distinction between norms and formalized "rules" is fuzzier than that between norms and laws (and accordingly more analytically problematic). Nonetheless, we would contend that it is still useful (or at least not incoherent) to distinguish between written, codified rules enforced by formal institutions on the one hand and non-codified, informally-enforced community norms on the other. See, e.g., West, supra note 5, at 20001 .

93 See ELLICKSON, supra note 1, at 123-24.

94 Donald C. Clarke, Dispute Resolution in China, 5 J. CHINESE L. 245, 248 (1991). 
moral authority stems precisely from their generalized social connections to disputants as fellow neighbors and sharers of a common social context. ${ }^{95}$ These two institutions are formalized and "public" in the sense that they are paid with public funds, have a mandate to represent community interests, and are established as government organs by formal elections or other legal procedures. Yet they are not able to apply coercive power in sanctioning parties, and they generally do not employ formal rules in resolving disputes. Some minimal level of formal procedure may be applied, especially by the Residents' Committee when summoned to mediate standing disputes, but this is often applied unevenly and tailored to the exigencies of individual cases.

This middle layer of non-legalistic public authority in Beijing Hutongs suggests that the traditional distinction between laws and norms should be reconsidered, or at least, the standard assumption that the use of informal norms precludes intervention by public institutions should be softened. As will be discussed, our field research suggests that institutionalized nonlegalistic public authorities can play a vital role in developing and enforcing informal social norms, and indeed they can often use norms to broker negotiations more efficiently and productively than purely private negotiators. Before discussing the specific mix of dispute resolution methods actually employed by residents, it will be useful to first introduce these unique but central institutional actors - the non-legalistic public authoritiesin more depth.

\section{B. Non-Legalistic Public Authorities I: The Residents' Committees ("Juwei Hui")}

To many contemporary Chinese urban residents, the term "juwei hui" evokes images of a group of women, largely housewives, ranging from 40 to 70 years in age, who are very (perhaps overly) enthusiastic about their neighbors' affairs. The younger generation, who often find the Residents' Committees activities too intrusive, often sarcastically refer to Committee members as "bound-feet detectives." 96 Yet despite such tongue-in-cheek

95 See Meares, supra note 88, at 393 (emphasizing the importance of "horizontal relationships" between government authorities and citizens in promoting law enforcement).

${ }^{96}$ The term "bound-feet" conveys two connotations. The first refers to the age of the typical women who worked for the neighborhood committees when they were first established in the early 1950s. As we will discuss later on in the Article, the first group of women recruited to work for the neighborhood committees tended to be those old-aged women who had lived in the particular neighborhood for a long time. As most of these women were born before the 20th century, they tended to have bound feet. The second 
caricatures, Residents' Committees have played and continue to play an important role in the provision of certain basic public services at the street level, including neighborhood dispute resolution. Indeed, during the course of our research, when asked what they do when they cannot resolve disputes among themselves, residents would invariably answer: "Go to the juwei hui."

Neighborhood Residents' Committee ("juwei hui"), though a term coined in the early 1950s, was not an novel invention of the current Chinese government. Historically, the Chinese judicial structure has received reinforcement from a community mutual-responsibility system known as the baojia system, which can be traced back to the early Han dynasty (206 B.C.220 A.D.). ${ }^{97}$ While the baojia system did not always perform as well as the central government had hoped, the concept of preserving an orderly community through mutual supervision and responsibility has persisted in Chinese society. ${ }^{98}$ When the Nationalists (Guomindang) overthrew the last imperial dynasty and established the first Chinese Republic in 1911, they found themselves again resorting to the baojia system, despite their eager efforts to reform all the traditional means of administration. ${ }^{99}$ The Guomindang government, however, failed to gain a tight control over the countryside and quickly saw the mutual-security system loosen amid constant internal warfare. ${ }^{100}$ Drawing upon this lesson, the Communist Party started its version of the baojia system early on its journey to power. While still fighting the Guomindang in the Civil War of 1945-49, the Communist Party instituted "mutual guarantee" groups in the communities it controlled, with each group composed of volunteers willing to supervise each other to ensure a reliable community. ${ }^{101}$

When the Chinese Communist Party (CCP) finally took over power in China in 1949, it organized study groups where citizens were made to learn

connotation refers to the womens' old-fashioned and often outdated but very stubborn way of doing things. Today, obviously, it is the second connotation people are emphasizing when they use the term.

${ }^{97}$ For further discussion of the baojia system, see generally MARK ELVIN, THE Patter of the Chinese Past (1973); Ping-Ti Ho, Studies on the Population of ChINA 1368-1953 (1959); KUnG-Chaun HSIAO, RURAL CHINA: IMPERIAL CONTROL IN the Nineteenth Century (1960); and Jonathan Spence, The Search for Modern CHINA 125-26 (2d ed. 1999).

98 See generally SPENCE, supra note 97.

99 Zhonghua Minguo Shigang [Brief History OF THE Republic of China] 41819 (Zhang Xianwen ed.); see also SPENCE, supra note 97, at 350.

100 See supra note 99.

101 Weinan Fang, Dangdai Zhongguoshi [CONTEMporary Chinese History] 353 (1997); see also SPENCE, supra note 97, at 456. 
about the new political regime and its ideology. ${ }^{102}$ Through such study groups, the CCP leadership gradually set up a network of street-committee branches. ${ }^{103}$ In addition to their purely political functions, the street committees, organized by neighborhood, also worked on public service projects such as street cleaning and maintenance, running night school programs for the illiterate, taking care of the elderly and small children while young adults were at work, supervising water and other utility supply, and administering health and vaccination programs. ${ }^{104}$ They also assumed the traditional public security responsibilities of their predecessors under the baojia system, monitoring their neighbors and enforcing various political policies ordered from above. ${ }^{105}$

In the early $1950 \mathrm{~s}$, these street-committee groups adopted the more formal title of Neighborhood Committee of Urban Residents ("chengshi jumin weiyuanhui," or its abbreviation "juwei hui") and were widely established in the traditional residential areas of Beijing. ${ }^{106}$ The CCP leadership, based upon its experience of rural mass mobilization, understood the vital importance of extending its power down to all sectors of society. It carefully recruited those who were enthusiastic about the Communist Party's political campaigns to participate in the newly established committees, especially female Party activists who stayed at home-and thus could police their neighborhoods-during the work day. ${ }^{107}$ While these committees were never formally part of the Party's organizational structure-their members were not required to be members of the $\mathrm{CCP}$-they were regarded as

102 See generally Essays in Part I, in 14 CAMBRIDGE HistoRy OF CHINA: THE PEOPLE's RePublic: THE EMERGENCE OF REVOlutionaRY CHINA 1949-1965 (Roderick Macfarquhar \& John Fairbank eds., 1987); MAURICE MEISNER, MAO'S CHINA AND AFTER: A HISTORY OF THE PEOPLE'S REPUBLIC (1986).

103 MEISNER, supra note 102.

104 Id.

$105 \mathrm{Id}$.

106 For this paper, we use the term "Residents' Committee" to refer to this institution.

107 See generally Christina K. GILMARTIN, ENGENDERING THE ChInESE REVOlution: RADICAL WOMEN, COMMUNIST POLITICS, AND MASS MOVEMENTS IN THE 1920s (1995). The Chinese Communist Party (CCP) already had a long history of mobilizing women first in its efforts to gain mass support in the countryside before entering the urban areas. Originally, they did this in accordance with their campaign of "liberalizing women." Later on, they realized the huge influence Chinese women could exert in their households and communities and began to consciously recruit women into its various movements. 
extended branches of the Party's municipal governments. ${ }^{108}$ Committee members were not formally compensated, and their services were considered voluntary before they were gradually professionalized in the late $1980 \mathrm{ss}^{109}$

Of course, the Residents' Committees also played a significant role in dispute resolution, just as their predecessors did under the old baojia system. This role was actually enhanced and expanded when the CCP leadership successfully banned all private practice of law and limited the application of legal expertise to certain government ministries and the state-controlled judiciary in the early 1950s. ${ }^{110}$ Additionally, Mao's influential 1957 article "On Contradictions" distinguished between what he envisioned as "innercontradictions among people" from "contradictions between people and their nemesis," and declared the latter must be handled through aggressive judicial action against "class enemies." 11 Thus, during this era, mere appearance in court carried a huge stigma. The Chinese people tended to envision law as a means of punishing class enemies through a system of courts and prosecutors who concentrated on the political rather than the legal aspects of given cases. ${ }^{112}$ As a result, most of what might be termed civil cases were handled

108 Interview with Residents' Committee, Jianguomen Wai District, supra note 22.

${ }^{109}$ In reality, they received different kinds of subsidies from the municipal government. Id. Many subsidies were intangible and could mean a lot to those who had to live through many political campaigns. Id. For instance, the members of these neighborhood committees could learn of many kinds of administrative policies earlier than the ordinary citizens and could make preparation in advance accordingly. Id. This privilege was of great significance when many varieties of food were supplied to urban residents on rations in the early 1970 s. Id.

110 The CCP viewed the steady growth of legal expertise which was cultivated in the later years of Guomindang rule a forceful threat to its dictatorship and dismissed most of the skilled practitioners in the legal profession in the 1950s. In 1959, the Ministry of Justice was abolished altogether, along with any organizations of lawyers. Law school students decreased and only studied political rather than legal matters at school. The Ministry of Public Security took over and dealt with both criminal and political offense as national-security matters. This situation lasted until 1978, when the government began to reassemble the rudiments of a legal system. For further discussions, see generally Chinese Family law and Social Change in Historical and Comparative PERSPECTIVE (David Buxbaum ed., 1978); CONTEMPORARY CHINESE LAW: RESEARCH Problems and Perspectives (Jerome Cohen ed., 1970); Victor Ho Li, LAW Without LAWYERS (1977); and HENRY ZHENG, CHINA'S CIVIL AND COMMERCIAL LAW (1988).

111 Mao drafted this article in 1957. THE SeCRET SPEeCHES of ChaIRMAN MaO FROM THE HUNDRED FLOWERS TO THE GREAT LEAP FORWARD 131-89 (Roderick MacFarquhar et al. eds., 1989) (transcript of original version of Mao's speech on the same topic). Mao's distinction between these two kinds of "contradictions" remained hugely influential upon people until late 1980s.

112 See generally Ho LI, supra note 110; ZHENG, supra note 110. 
at the local city-ward level by mediators. Neighborhood Residents' Committee members often assumed this responsibility. ${ }^{113}$

As economic reforms gathered momentum after the Mao era ended in 1976, the context within which Residents Committees operated underwent dramatic change. The more affluent Hutong residents started to move to newly built apartment buildings where they could enjoy more privacy and greater creature comforts. Even for those who stayed on, a general decentralization of political power rendered the central CCP leadership less forceful and penetrating. People began to resist surveillance, supervision, and criticism from their neighborhood Residents' Committees. ${ }^{114}$ Most Hutong residents now wanted their neighborhood Committee members to act not as agents of the government, but rather as respected members of the community who could provide public services and effective mediation without the taint of political ideology.

Under such circumstances, both reform-minded intellectuals and ordinary citizens called for the professionalization and democratization of the Residents' Committees. ${ }^{115}$ In response, many former members of the Committees resigned under great social pressure, and this led to the direct election of some Residents' Committees in the late 1980s. ${ }^{116}$ Local municipal governments also instituted systematic reforms that included hiring more qualified personnel for positions in the Residents' Committees, providing training courses in dispute resolution, and paying these professionals regular annual salaries instead of merely providing them with subsidies. ${ }^{117}$

113 Id.

114 It was during this period of time that the nickname for the neighborhood committee members, "bound-feet detectives," appeared and quickly spread all over the country. Young people especially enjoyed ridiculing these neighborhood activists. Residents' Committee members who years earlier were labeled model mediators by CCP newspapers now surely had become laughingstocks.

115 This trend was discussed in several of our interviews, including Interview with Residents' Committee, Jianguomen Wai District, supra note 22.

116 Grass-roots democratization and direct election at the neighborhood level, together with its counterpart at village level in the countryside, presents a complicated issue that cannot be fully covered in this section. Suffice it to say that it is a movement that is still ongoing and deserves further study.

117 When we visited the neighborhood committees, we were very impressed with the size of their offices and the staff who worked there. While many committee members used their own households as offices in the previous decades, nowadays, they work in quite formal office spaces, equipped with many file cabinets and bookshelves. One such committee has five offices located in five different alleys of the neighborhood. Most of 
Committee members today are assigned to different departments in charge of different administrative functions, and they need to attend regular training sessions at the municipal level. ${ }^{118}$ Official guidelines promulgated by the municipal government now require that Committee members who work as dispute mediators be "fair-minded, linked with the masses, enthusiastic about mediation work, cooperative with fellow workers, and equipped with a certain level of knowledge about the law and current policies." 19 The Residents' Committees in Beijing Hutong areas still serve as extended branches of the central government for the purposes of publicizing and implementing certain national policies; however, the scope of this function is much more limited than in previous decades. ${ }^{120}$ During our research interviews, Committee members and residents alike listed the following policy areas - often in coordination with the local government-as being administered by the Residents' Committees: national family planning policies, ${ }^{121}$ campaigns against prostitution and drug addiction, the administration of certain forms of social welfare, ${ }^{122}$ and providing mediation in civil disputes among the residents. ${ }^{123}$ Although residents vehemently resist

the staff are still women, but they are much younger in age and better educated. Many had worked outside the neighborhood but had been laid off due to the economic reforms.

118 Interview with Residents' Committee, Jianguomen Wai District, supra note 22.

119 Guidelines on Electing Neighborhood Residents Committee Members, Neighborhood Residents' Committee Office, Yabao Hutong, Beijing (Sept. 6, 1995) (on file with authors). Note that the previous requirement of a correct political attitude was discarded and the need for a certain level of legal knowledge was added. This change reflects the general trend of having neighborhood dispute mediation less politicized.

120 Interview with Residents' Committee, Jianguomen Wai District, supra note 22.

121 This function is still closely related to the Committees' control of household registration information, a traditional function of such neighborhood groups. The members are still responsible for paying close attention to those who live in their neighborhood and their guests to ensure no "outside-plan" pregnancy. They are fined if they fail to perform this function and more births occur than allowed.

122 Interview with Residents' Committee, Jianguomen Wai District, supra note 22. This includes periodically compiling the records of those who need various government subsidies or compensations, updating data about household registration, and distributing welfare money. They also organize various programs for those elderly people who do not have support, as well as some child care. It is rare for them to organize activities like street-cleaning or groups studies these days, but some neighborhood committees are now raising funds to establish neighborhood reading-rooms and entertainment centers. A serious task they have to deal with nowadays is trying to come up with ways to help those workers who have recently been laid off. Many committee members touched upon this issue but were reluctant in further discussions. Id.

123 See discussion infra Part VI. 
unwanted interference in their household affairs, they insist that in other areas of life the Committees provide invaluable services as mediators.

As will be discussed more fully in a later section, Residents' Committee mediation is still deemed the most appropriate means for resolving minor disputes involving real property, debts, nuisances in the neighborhood, marital or family problems, ${ }^{124}$ and compensation for minor damages or injuries. In mediating resolutions to these disputes, Residents' Committee members still regard preserving community harmony and preventing social disturbance as their primary goal. In the course of these efforts, shared community norms, not formal laws, structure the mediations and inform eventual resolutions. Written rules are almost never invoked in this process, and disputes are generally resolved according to shared community social norms. Commitments to cooperation, reciprocity, and preserving existing social relationships are much more important than actual statutes or ordinances. Additionally, as the Residents' Committee has no coercive sanctioning power of its own, achieving resolutions always depends upon the mutual agreement of the parties to the dispute. ${ }^{125}$ An internal Residents' Committee case record describes the dispute resolution process as follows:

When we carried out our mediation task, we tried to talk to both sides instead of just one. We always made efforts to make sure that they could perceive the dispute issue from the perspective of the other side. In doing this, we reasoned with them using common norms and morality and we persuaded them through touching them emotionally. While we are against "unprincipled mediation" with the only goal of reaching a compromise without paying attention to who is right and who is wrong, we do think that, in ordinary disputes, it is important for both sides to be more considerate of the other side and to be willing to compromise on those matters which do not concern principles. ${ }^{126}$ This is a excellent tradition of our nation and we need to preserve it in order to best serve our public values and interests. ${ }^{127}$

124 In our interviews, a number of residents responded to our question regarding family disputes by emphasizing that many such disputes actually reach a better resolution when mediated by neighborhood committee members. When we pressed about the traditional principle of not letting family discord known to the public, they pointed out the changing environment and generation gaps. They stated that many young people paid less attention to family unity than before and their parents were thus often forced to seek outside help. For further discussion, see infra Part VI.

125 For more detail on this mediation function, see infra Parts V, VII.

126 The meaning of the word "principle" in China has undergone significant changes in recent years. Before the $1980 \mathrm{~s}$, it was used to mainly refer to the CCP's political 
In short, despite the continuous shifting of political policies in the decades since 1949, the mediation of minor disputes in Chinese society has maintained most of its traditional characteristics in the hands of the neighborhood Residents' Committees. ${ }^{128}$ The Committees represent a unique institution that is still vital to effective street-level dispute resolution in present-day urban China, and, as in times past, this institution derives its relevance and authority principally from traditional cultural preferences for mediation, government support of its activities, and adherence to the shared social norms of its constituent residents. One Hutong resident summarized it nicely:

A lot of changes have taken place since the 1980s, and there has been more and more talk about resorting to legal means. But traditional consciousness cannot be replaced within a short period of time, and the law remains a long distance from ordinary people. Unless there is really no other alternative, we common residents simply are not willing to litigate against each other in the courts. These neighborhood Residents Committees, though far from perfect, do provide useful forums for helping ordinary citizens resolve their disputes without going to court. ${ }^{129}$

The specific community norms that inform Residents' Committee mediations-as well as private negotiations between neighbors-will be discussed at length in Part IV of this paper. But first, we must address one other distinctive "non-legalistic public authority" that is central to street-level dispute resolution in Beijing Hutongs-the Neighborhood Police.

policies and the residents' attitude towards these policies. Today, it concerns much more about the public norms of morality and justice.

${ }^{127}$ Record of a dispute resolution case filed with the neighborhood Residents' Committee office located at Jinbao Hutong, Beijing (Mar. 11, 2002).

128 The interaction between tradition and various political campaigns was a common topic mentioned by committee members when we conducted our interviews. They kept emphasizing that political campaigns come and go, but the goal of their mediations was a traditional and a long-term one: to keep the harmony of the neighborhood. In achieving this goal, they had to use political rhetoric in order to make their agreements sound politically correct under various political circumstances, but the theme of reaching a dispute resolution through reasonable compromise and conforming to public standard of norms was always persistent.

129 Interview with Resident Group, Yabao Lu Hutong neighborhood (Aug. 26, 2002) (notes on file with authors). The person who gave this comment is a middle-aged woman who had lived in that neighborhood for 47 years, and those who were present all nodded in agreement. 


\section{Non-Legalistic Public Authorities II: Neighborhood Police ("Pianer Jing")}

Between the neighborhood Residents' Committees and the formal legal institutions of the state exists another semi or sub-administrative mediation agent: the Neighborhood Police ("pianer jing"). Although they are a part of the formal police system and they do wear police uniforms, Neighborhood Police officers are clearly distinguished from the other, more formal sectors of the police bureau. They constitute a special section of the police force charged with guarding their assigned neighborhoods and serving as mediators when they encounter disputes among residents. ${ }^{130}$ Although summoning public authorities to resolve neighborly disputes is often regarded by Hutong residents as a hostile and anti-social act, relying on the local Neighborhood Police officer for mediation is apparently widely accepted as standard practice.

One major difference between the Neighborhood Police and the rest of the police force lies in their standard mode of operation. Usually one Neighborhood Police officer is assigned to a residential area under the purview of a single Residents' Committee, generally consisting of about three to eight Hutongs - depending on the geographical size of these Hutongs and their population densities. ${ }^{131}$ The Neighborhood Police officers come to residents without being summoned; indeed they conduct an informal "troubleshooting" tour of their assigned Hutongs each day, and they are familiar with almost every family within these neighborhoods. Most of the officers have grown up in a similar residential environment, and through their work, they have learned to identify with the specific interests and concerns of their assigned Hutong neighborhood. ${ }^{32}$ According to one Hutong resident, "pianer jing are not considered 'real' police, as they are not formal. They are more like mass workers or mass mediators who help the neighborhood people solve their difficult problems, including disputes."133

${ }^{130}$ Due to the lack of scholarly literature on this issue, description of many of their functions are denied from our observation and conversations with the neighborhood policeman who kindly agreed to take one of us on one of his routine tours through the Hutong neighborhood.

131 Interview with Police Officer, Yabao Lu Hutong Neighborhood (Aug. 27, 2002) (notes on file with authors).

132 Id.

${ }^{133} \mathrm{Id}$. By using the term "mass workers," Mr. Lin invokes an image of these neighborhood police performing political rather than legal functions. Meanwhile, it also implies that the neighborhood police are considered insiders rather than outsiders in the social network of the Hutong communities. 
Neighborhood Police officers do not have their offices in official police bureau buildings. Rather, they have their own small offices in the neighborhoods they are assigned to, and they go to official police bureau offices only to attend meetings or make special reports. Many of them do not even use their small neighborhood offices very often, as they are out making their rounds in the Hutongs for most of the workday. "The residents' houses are our posts," said one officer. ${ }^{134}$ The neighborhood police also often do not don their uniforms when working in the neighborhood, although the residents clearly know who they are. Additionally, the officers do not carry any weapons and they ride bicycles rather than drive police cars. ${ }^{135}$

An examination of the roles performed by the Neighborhood Police during their daily rounds through the Hutong neighborhoods confirms the fundamentally extralegal, norm-based nature of their mediation and patrol activities. During the course of our research, we had an opportunity to accompany one Neighborhood Police officer on his daily rounds in the Yabao Lu Hutong district. Rather than offer abstract generalizations about Neighborhood Police functions, it is probably more illuminating to give a brief summary of the things this officer actually did over the course of his workday.

His day started at 8:00 a.m., when he rode his bicycle into Yabao Lu Hutong. He first stopped by the office of the Hutong's Residents' Committee and chatted with the people working there, asking them whether there was any information he needed to know. The Committee members exchanged some information about the residents' birth control program with him.

He then went to a household in which both the husband and the wife had recently been laid off from a state-owned enterprise. There, he talked with them for about an hour, providing information about potential employment and educational opportunities while they complained about their situation. He then wrote them a certificate which would be helpful in having their child's school tuition waived, though it needed to be approved and stamped by his boss.

From there, he went to visit an elderly man who was sick in bed and whose adult children were away in other cities. He helped the old man pick up his gas stove and confirmed that the old man was getting money from his kids regularly. He reiterated to the old man that he had a legal right to be supported by his adult children and that he could bring them to court if they

134 Id.

135 An illustrative example is that they usually do not stop drivers who violate traffic rules, though they might write down the relevant information and have such information sent to their colleagues. Id. 
did not perform this obligation. After that, he was invited to have lunch in the household of one resident whom he referred to as "an old friend."

In the afternoon, he paid a visit to a family whose son was doing jail time in a different province and told them to keep writing letters to the son to encourage him. The family complained to him about being discriminated against in their neighborhood because of this, and he promised to do something about it.

Next, the officer went on to a courtyard and called two neighbors together to talk with them about a long-term dispute they have with each other. The dispute originated when one neighbor claimed that the other had spread irresponsible rumors about his wife and now the two households refuse to talk with each other. The neighborhood policeman obviously had talked with them about this issue before, and he tried hard to initiate a dialogue between the two parties through "persuasive reasoning and emotional appeals." $136 \mathrm{He}$ also pointed out that their discord had made the other families in the courtyard feel an awkward tension, and that all their neighbors were eager to see them make up. ${ }^{137}$

In performing these kinds of tasks, the Neighborhood Police seek to provide community services rather than enforce legal regulations. In this sense, they more or less perform the traditional role of a headman or a clerk to the magistrate courts in earlier historical periods. When China first organized its professional police force towards the end of the Qing dynasty, the police retained this traditional function of serving as mediators for local disputants. ${ }^{138}$ In fact many members of the first post-imperial Beijing police force were former Manchu bannermen, themselves Hutong residents and skilled mediators among their neighbors. ${ }^{139}$

136 Id.

137 Amid these routine visits, the policeman did admit that he often felt bored with these tasks, but he enjoyed the trust and bonding he shared with the Hutong residents he talked with. He once described his role as a "caretaker." Id.

138 For a full account, see LIANG SHIQIU, LIANG SHIQIU SANWEN 162-65 (Zhonguo Guangbo denshi Chubanshe 1989). As Liang describes it, these first generation police saw themselves more as clerks than as policemen. Their position was not as prestigious as professional law-enforcers but rather local guards ensuring orderly relationship among the neighbors. They were not accorded high authority and could only earn respect and authority through their personal skills. The reason was that Chinese tradition had power to enforce laws and rules retained in the administrative system and the army, while the police were a newly-formed force under the Western influence and part of the new statebuilding program of the late Qing and the early Republic period. Id.

139 Id. 
Under the communist regime, the state saw the police as an effective means to thrust totalitarian political institutions into every sector of Chinese society. In order to strengthen the CCP's control of the entire citizenry, the regime designated a special branch of the police force to function as a semiadministrative agency, monitoring city residents along with the neighborhood Residents' Committees. ${ }^{140}$ These special Neighborhood Police were officially charged with preventing or suppressing any potential public disturbance before it posed a threat to government authority. ${ }^{141}$ In this respect, the political mission of the Neighborhood Police overlapped with that of the neighborhood Residents' Committees discussed above. ${ }^{142}$ From the 1950 s to the 1970 s, police mediation was largely politicized as a method of enforcing state policies. Officially at least, the Neighborhood Police aimed at enforcing politically correct thought and behavior among the Hutong residents. 143

In practice, however, the Neighborhood Police retained many of the more traditional headman functions, even during these politically charged eras. They still defined their role as mediators according to the more traditional, custom-based dispute resolution regimes that had functioned in their native neighborhoods for generations. While the state asked them to literally enforce government policies, in reality they more often adhered to the traditional preference for compromise while paying lip service to political rhetoric. ${ }^{144}$ One Neighborhood Police officer made this point quite succinctly: "The way we mediate here is that while the central government has central policies, we have our own ways of dealing with them."145 According to both Hutong residents and the officers themselves, the reason for this is simple: Mediation can only be productive through compromise and flexibility.

140 Interview with Police Officer, Yabao Lu Hutong neighborhood, supra note 131.

141 Id.

142 For discussion of the Residents' Committee, see supra Part IV.

143 According to the neighborhood policeman we followed, the chance of their career promotion is closely related to the rate of crime and public disturbances in their respective residential areas. Although going to court or calling the police to solve disputes is no longer considered public disturbance as of today, it still does not reflect well in the evaluation of a neighborhood Police officer's work. "The best result we try to achieve," he said, "is harmony without any discord in our neighborhoods. While it sounds impossible, we hope to at least dissuade some of these discords through our peaceful mediation." Interview with Police Officer, Yabao Lu Hutong neighborhood, supra note 131.

144 Id.

145 Id. 
To conduct their mediation work effectively, the neighborhood police work hard to be on good terms with the Hutong residents. They also maintain their own "reliable information network" through which they can learn of problems without being summoned by the disputants themselves. ${ }^{146}$ Officers generally approach disputants as fellow members of the community so that they do not appear too official or imposing. ${ }^{147}$ To gain trust from residents, they present themselves not as agents of the government or the police bureau, but rather as real members of the community, only with more experience, wisdom, and authority. Accordingly, their authority seems to come more from the sense of justice they exhibit in their mediations than from their official titles as police officers. ${ }^{148}$ As the residents and the Neighborhood Police both told us, the success of their daily job, and thus their career, depends more upon their solid and trusting relationships with Hutong residents than their official power, which is negligible. ${ }^{149}$

In the mediation process itself, the main goal is to uphold community social norms and preserve relationships among neighbors rather than disrupt them. The Neighborhood Police thus often base their mediation approach upon the twin principles of community harmony and reciprocity, persuading disputants to assess their own positions from this same perspective. As in mediations performed by Residents' Committees, formal legal rules are

$146 \mathrm{Id}$.

147 In one instance, a Neighborhood Police Officer learned through casual conversation with residents that the relationship between two neighbors was becoming strained and a fight might take place. He took the initiative to investigate the facts and intervene as a mediator. Upon learning that the dispute was over the amount of electricity fee one resident ought to pay, the officer approached the one who demanded payment first and calculated with him the electricity fee for the previous year. Then he approached the neighbor owing money by explaining the situation from a neutral standpoint. This worked, he explained, because it was easier for the two parties to calm down and become more willing to assume their own responsibility when he intervened as a third-party in an informal way. $I d$.

148 Though this statement is at least somewhat doubtful as one wonders how any individual could clearly distinguish between these two aspects, especially within the Chinese political context, almost all the residents we talked with emphasized this point. They actually told us about a certain neighborhood policeman who was quite corrupt as a mediator and would take side with any party who bribed him. That policeman totally lost their respect and trust and had to be removed in the end. Id.

149 "Pianer jing" is the lowest rank for any police officer under the current police system in China. Many of them do not have the right to be equipped with weapons. Therefore, they need to do their job really well in order to be promoted to the higher rank of the police system and to be accorded more power. 
almost never applied, and coercive sanctions cannot be imposed directly. ${ }_{1} 50$ One neighborhood policeman explained this approach in some detail:

In mediating disputes by smoothing away any social discord, we prefer to use extra-legal means rather than formal legal rules as the traditional means often better reflect the need to place oneself in the other party's shoes. The principle of reciprocity is the best to preserve a good relationship between the neighbors. This time, you give up some interests while the other side gains, but next time you will gain while the other side remembers what you did earlier and willingly give up some of their private interests. This traditional way of Chinese thinking has worked for us for over two thousand years and there is a reason for that. Today's legal rules are based upon similar moral standards but they are also based upon discrete fact patterns. When the relationship between the neighbors is a continuous one rather than an isolated one, resorting to these legal rules without any room for compromise and reciprocity would deeply hurt people's feelings and lay foundation for more future discords. Furthermore, it is still easier for us common people to accept traditional ideas than the new legal terms and rules despite the government's efforts to implement the rule of law today. $\mathrm{We}$, as commoners, as long as we do not commit crimes, find it better to follow extra-legal but just and historically proven moral norms. ${ }^{151}$

Thus, quite apart from the activities of the Residents' Committees, the Neighborhood Police act as an additional fundamentally non-legalistic mediating authority that Hutong residents can consult when disputes occur. They serve as an important link between more formal legal dispute resolution channels and the Hutong residents' social practice, and they rely primarily upon informal community norms in gaining residents' trust and mediating between disputants. While they may refer to legal rules in their mediations, especially during today's era of legal reform, ${ }^{152}$ they do not structure their mediations according to legal rules. Instead, they see their success as mediators depending primarily upon their skillful deployment of local norms and customs.

In sum, Hutong residents have several institutional options in resolving their disputes with neighbors. As has been discussed in this section, these options span vastly different sets of institutional actors and imply differing levels of legalism, formalism, and coercive state power. Most interesting here

${ }^{150}$ In rare cases, the Neighborhood Police might report a particularly serious dispute to their colleagues at the police bureau, but this is rarely done and, in any case, residents can call the municipal police themselves if they are so inclined.

151 Interview with Police Officer, Yabao Lu Hutong neighborhood, supra note 131.

152 See supra Part IV (describing a Neighborhood Police officer's daily rounds). 
are the unique set of "non-legalistic public authorities"-the local Residents' Committees and the Neighborhood Police - that lie somewhere between the domains of private bargaining and public law. We will now turn to a more detailed examination of our research results and discuss exactly which dispute resolution methods Hutong residents prefer for certain common dispute types, and why they tend to prefer these methods over others.

\section{The PRIMACy of NoRMS IN HUTONG Dispute RESOlUtion}

As mentioned in the opening passages of this paper, a rich literature has underscored the primacy of informal norms in governing relations between individuals in a wide array of legal, institutional and social contexts. ${ }^{153}$ Extralegal norms, ${ }^{154}$ it has been found, may be especially important in what Robert Ellickson has termed the "close-knit" group: "a social network whose members have credible and reciprocal prospects for the application of power against one another and a good supply of information on past and present internal events." 155 In such communities, strong intra-group social ties not only facilitate the creation of potent group-specific norms, but also allow members of the community to enforce these norms through informal, extralegal sanctioning of intransigents. ${ }^{156}$

In fact, our field research revealed a strong universal preference for norm-based, informal methods of dispute resolution among Beijing Hutong residents. The residents we interviewed reported a distinct bias against using formal legal rules or involving formal legal authorities in their affairs, which they generally regarded as inefficient and potentially troublesome. Of the 65 Hutong residents we interviewed, many of whom had lived in the same neighborhood since the 1950 s, not one had ever hired a lawyer or been

153 See discussion supra Part I.

154 Of course one must be careful in using the term "norm" to explain human behavior. As Cass Sunstein has cautioned, "norms" really explain nothing if they are cited to account for "any apparently anomalous result" that appears exogenous to the prevailing legal regime. Sunstein, supra note 9, at 945. For the purposes of this paper, "norm" simply refers to an extra-legal principle or social understanding, not codified but shared by the members of a community, which may be used to determine individual entitlements or otherwise guide resolution of disputes. Such a "customary norm emerges in a community when it is internalized by enough members," and long-standing social practice, rather than formal institutionalization, confers legitimacy and predictability on the dispute resolution regimes that it governs. Robert D. Cooter, Law and Unified Social Theory, 22 J.L. \& SOC'Y 50, 63 (1995).

155 ELLICKSON, supra note 1, at 181.

156 See id. 
involved in litigation, and none reported ever calling the police about a dispute with a neighbor. ${ }^{157}$ In fact, most were quick to insist that relations with their neighbors were harmonious, and that they were not the kind of contentious people who would involve public authorities in private disputes.

Residents similarly reported a disinclination to summon third-party mediators from the Residents' Committee or the Neighborhood Police unless it was absolutely necessary. Despite the informal, rule-free nature of such mediations, less than one third of the residents in our interview sample reported seeking mediation through either of these institutions. ${ }^{158}$ Nonlegalistic public authorities like the Residents' Committee did appear to play a prominent role in the life of the community generally, however, as almost all interviewees reported regular contact with Residents' Committee members and Neighborhood Police Officers in some capacity. ${ }^{159}$ Many interviewees also reported participating in Residents' Committee mediation of disputes involving other residents. But the vast majority of the residents we interviewed insisted that they preferred never to initiate third-party mediation. A baseline preference for informal, ad hoc, neighbor-to-neighbor negotiations was thus a constant refrain in our interviews, with norm-based mediation by the Residents' Committee or Neighborhood Police being a viable second choice, while invocation of formal rules (of any kind) or

157 As will be discussed later in this section, residents did report that individuals in their neighborhood had called the police or consulted with lawyers on rare occasions, but all of our 65 interviewees insisted that they had never resorted to such measures themselves.

158 Twenty of the 65 residents interviewed $(31 \%)$ reported personally summoning the Residents' Committee to mediate a dispute. Sixteen of these were residents identified in Resident Committee dispute records, while just four of them were from interviews of randomly selected residents. This suggests that the actual rate percentage of residents who have summoned Residents' Committee mediators may be much smaller than $31 \%$. It should be noted also, however, that many residents reported being at least peripherally involved in dispute mediation, often concerning disputes involving third parties. Aversion to involving Residents' Committee mediators in private disputes varied somewhat by neighborhood, with residents in some areas reporting almost no use of such institutions, while others reported consulting third-party mediators only on rare occasions (perhaps once or twice per family). In all cases, there was a clear preference to avoid third-party mediation if private neighbor-to-neighbor negotiations were possible.

159 The Residents' Committee in particular serves several functions beyond mediating dispute resolutions. The Residents' Committee typically is responsible for seeing to repairs of public, street-level property, arranging for neighborhood garbage collection, carrying out government propaganda campaigns, and overseeing implementation of the national one-child policy. Thus, even though residents generally disfavored involving the Residents' Committee in private disputes, they generally had a lot of contact with the Committee in these other areas. 
resorting to formal legal institutions were highly disfavored and accordingly rare.

Over $90 \%$ of the residents we interviewed reported that there are no written rules governing the use of common courtyard areas in Hutong neighborhoods. ${ }^{160}$ In other words, there are no official nuisance rules as that term is understood in the West. Instead, informal social norms dictate that each household may use the area around its doorway (roughly two square meters in area) in any way it wishes. ${ }^{161}$ The remaining courtyard areaswhich generally account for most of the space in any given courtyard-are recognized as common space, and any proposed use of these areas must be approved by the other households adjoining the courtyard (i.e., any single neighbor is able to veto any proposed use). ${ }^{162}$ This creates a variant of what Heller has termed an "anticommons" in common courtyard areas. ${ }^{163}$ Alternatively, to invoke Calabresi and Melamed's oft-cited typology, this scheme effectively grants all residents two entirely norm-based property-rule entitlements: one allowing them absolute control of designated household areas near their doorways and another granting them veto-power over proposed uses of common areas. ${ }^{164}$

Under this regime, direct neighbor-to-neighbor bargaining generally resolves uncertainty as to what uses of common space are acceptable, just as the Coase theorem would predict, ${ }^{165}$ and the preferences of nearby neighbors are generally respected in this process. Of course, obstinate neighbors or particularly noxious uses or encroachments on common space can lead to intractable disputes. The Residents' Committee will step in to mediate between parties when private negotiation fails. We interviewed members of

160 Specifically, 33 of 35 residents in one interview set (94\%) confirmed this fact.

161 This norm was consistently cited in our field interviews, and seemed to represent something of a universal norm of property entitlement. As far as the residents are aware, it has no basis in Chinese law.

162 See id.

163 Heller discusses this concept with regard to intellectual property rights in the biomedical field in Michael A. Heller \& Rebecca S. Eisenberg, Can Patents Deter Innovation?: The Anticommons in Biomedical Research, 280 SCIENCE 698, 698-99 (1998).

164 For Calabresi and Melamed's celebrated distinction between property rules and liability rules, see Guido Calabresi \& A. Douglas Melamed, Property Rules, Liability Rules, and Inalienability: One View of the Cathedral, 85 HARV. L. REV. 1089, 1105-15 (1972).

165 For Ronald Coase's revolutionary theory of determining individual entitlements through extralegal bargaining, see R.H. Coase, The Problem of Social Cost, 3 J.L. \& ECON. 1, 8-44 (1960). 
one household who had summoned the Residents' Committee to mediate a dispute with a neighbor who insisted on raising pigeons-and hence allowing them to discharge certain bodily functions--directly above the complainants' doorway. ${ }^{166}$ Another case we encountered involved a resident whose pet dog repeatedly relieved itself in common courtyard areas. ${ }^{167}$ In both cases, the Residents' Committee successfully intervened to vindicate the norm-based entitlements of the complainants, persuading the offending party to avoid such messes. ${ }^{168}$ Disputes over the use or expansion of kitchen facilities in courtyard areas also appeared typical, ${ }^{169}$ with private negotiations or Residents' Committee intervention similarly serving to uphold norms protecting property entitlements in courtyard spaces.

Resolution of noise complaints are also the exclusive province of informal norm-based solutions. The prevailing norm dictates that residents refrain from making more noise than is "necessary" under the circumstances. ${ }^{170}$ Residents' Committee mediators whom we interviewed reported that they were often summoned to mediate sometimes colorful disputes between neighbors embroiled in escalating battles of intrusive noisemaking. ${ }^{171}$ In one memorable case, a family responded to the noisy activities of a neighboring child by repeatedly banging on the walls and heating ducts connecting the two residences. The other family responded by encouraging the child in question to make as much noise as possible over the next several days. The Residents' Committee was eventually summoned to

166 Interview with Residents' Committee, Jianguomen Wai District, supra note 22.

${ }^{167}$ Interview with Resident Group, Yabao Lu Hutong neighborhood, supra note 129.

168 In the latter case, the Residents' Committee had actually promulgated an unofficial local policy against dog ownership to avoid precisely this problem. After suffering repeated transgressions, the complainants considered consulting higher government officials, but decided against it because there was no apparent official legal rule supporting their position.

169 At least three interviewees offered unsolicited examples or accounts of such disputes, while others made general reference to their occurrence within the community. Kitchen facilities are commonly placed in or near courtyard areas for ventilation reasons, thus they often physically infringe on common space or otherwise compromise public use of these areas by generating smoke, odor, or refuse.

170 In American nuisance law, "reasonable" would likely be the operative adjective, but the residents we interviewed consistently referred to the normative standard by using the word "necessary."

171 Since Hutong residences are typically extremely old and often poorly constructed, they do not absorb noise very well. Accordingly, noise-related disputes are common, cited by a large number of our interviewees as examples of typical conflicts between neighbors. 
admonish both parties to limit noise emissions to the minimum level demanded by their daily activities. No codified rules or standards were ever invoked, but there were no further complaints from either family. ${ }^{172}$

Residents' Committee mediators also reported applying this "necessity" norm to noise disputes between residents and nearby construction teams or neighbors conducting renovations. ${ }^{173}$ In such cases, construction projects and renovations are generally considered "necessary," but the parties responsible for them are commonly asked to make some kind of concession to the aggrieved. ${ }^{174}$ In one case, this involved money payments from a construction team to a nearby resident; ${ }^{175}$ in another, a family was persuaded to alter the daily schedule of its renovation work to accommodate an elderly neighbor's afternoon naps. ${ }^{176}$ Again, legal nuisance rules were never invoked by any of the parties to these disputes.

Informal social norms similarly govern most cases of property damage. Shared norms dictate that residents should compensate others for property damage wrought by themselves or by their children, unless they are financially unable to pay. Generally, parties bargain privately to determine the amount of the damage payment. However, if parties cannot agree on a fair amount, or if the accused party denies responsibility for the incident, the Residents' Committee may be required to intervene. One Residents' Committee mediator recounted an incident in which a child destroyed a neighbor's roof-mounted television antenna. The child's parents resisted paying damages on the grounds that a child could not be held responsible for these types of destructive activities. The Residents' Committee intervened and convinced the child's parents to pay for professional repair of the antenna; however, they also suggested that the aggrieved family repair their roof, since damaged roof tiles may have contributed to the accident. ${ }^{177}$ Despite close parallels to the American comparative negligence standard of tort liability, this solution was completely extralegal, and no reference was made to formal Chinese law. ${ }^{178}$ Cases of catastrophic property damage may

172 Interview with Resident Group, Jianguomen Wai Hutong neighborhood, supra note 35 .

173 Interview with Residents' Committee, Jianguomen Wai District, supra note 22.

174 Id.

175 Id.

176 Interview with Resident Group, Yabao Lu Hutong neighborhood, supra note 129.

177 Interview with Residents' Committee, Jianguomen Wai District, supra note 22.

$178 \mathrm{Id}$. This dispute also reflects the Chinese tradition of mutual compromise, whereby both parties to a dispute are encouraged to make concessions. 
require using formal legal institutions, especially when these incidents also involve bodily injuries, but these contingencies will be discussed in the next section. ${ }^{179}$

The cases and dispute types cited here merely represent some of the clearer, more memorable examples of the Hutong dispute resolution regime's overall norm-based orientation. While certainly not an exhaustive account, these examples are representative of general Hutong dispute resolution practices, and they allow one to glimpse the complex, norm-driven world uncovered by our research. While it is clear that Hutong residents commonly structure their world according to norm-based individual entitlements and the informal mediation activities of non-legalistic public authorities, such as the Residents' Committee, the considerations that drive these preferences are nuanced and complex. It is to this topic that we now turn.

\section{Why NORMS?: COST-BENEFIT ANALYSIS AND THE CHOICE BETWEEN NORMS AND LAW}

Some have advanced cultural or legal-development explanations to account for the primacy of extralegal norms in certain communities. ${ }^{180}$ With respect to urban Chinese communities specifically, one study observed that, in intra-group conflicts, U.S. ethnic Chinese rely on gossip and "informal social pressure" to resolve disputes, while members of other ethnic groups appear more likely to file lawsuits against each other in court. ${ }^{181}$ Certainly, deep-rooted cultural morays have a role to play in establishing community practices, but other research suggests that resort to extralegal norms may be the result of pragmatic, efficiency-driven considerations. ${ }^{182}$ Once strong social norms are established, it often becomes more efficient to structure certain interactions according to extralegal norms rather than codified legal rules. ${ }^{183}$ As Lisa Bernstein concluded in her study of contract relationships in modern business settings, "[r]ational transactors might deliberately leave aspects of their contracting relationship to be governed, in whole or in part, by extralegal commitments and sanctions." 184 Resort to informal social norms in dispute resolution thus does not necessarily evidence a lack of

179 See infra Part VI.

180 Merry, supra note 8, at 899, 913.

181 Id.

182 Lisa Bernstein, Merchant Law in a Merchant Court: Rethinking the Code's Search for Immanent Business Norms, 144 U. PA. L. REV. 1765, 1788 (1996).

$183 \mathrm{Id}$.

$184 \mathrm{Id}$. 
sophistication or legalism in the community at issue, but may rather represent rational calculations of costs, benefits, and the comparative efficiency of social norms versus legal rules in a given context. ${ }^{185}$

In fact, these sorts of comparative efficiency considerations are exactly what our field research uncovered in Beijing Hutong communities. According to our interviews, individual cost-benefit analysis often proves decisive in the selection of dispute resolution methods by Hutong residents. Rational calculations generally led individuals to choose informal, normbased, extralegal mechanisms, such as neighbor-to-neighbor negotiations or norm-based mediation by the Residents' Committee, over recourse to formal legal institutions. ${ }^{186}$

\section{A. Time, Money, Uncertainty and Social Disruption: The Many Costs of Formal Legal Solutions}

Among the prototypical elements of any cost-benefit calculation are monetary costs and time requirements, and these figured prominently in Hutong residents' evaluation of their dispute resolution options. Most interviewees seemed genuinely amused by our inquiry as to why they never consulted with lawyers or engaged the machinery of the court system. Their grinning answers were quick and uniform: "I don't have the money or the time." 187 None of the individuals we interviewed had ever seriously considered hiring a lawyer, largely because lawyers are prohibitively expensive to retain. At a citywide average of roughly $\$ 1,500$ to $\$ 2,500$ (U.S.) per year, the income of a normal Hutong resident is not sufficient to pay attorney's fees, even in China's nascent legal services marketplace. ${ }^{188}$ Apparently, at one time the Beijing municipal government made lawyers

185 See Ellickson, supra note 80 , at 686 (finding that rational calculations of the transaction costs associated with formal legal solutions generally lead California cattle ranchers to base individual entitlements on informal norms); West, supra note 5 , at 165 , 200-01 (observing that the Japanese National Sumo Association uses both informal norms and formal rules to govern its operations and that the choice to apply either rules or norms is "based on a calculation of [the] comparative efficiency" of each in maximizing group welfare-much like more formal firms in the West); West, supra note 4, at 304 (finding that Japanese citizens often choose norm-based methods over formal litigation in resolving noise pollution disputes based on calculations of cost).

186 Cf. West, supra note 4, at 303-04 (finding that Japanese citizens often choose norm-based methods over formal litigation in resolving noise pollution disputes based on calculations of cost).

187 This a paraphrase of the general thrust of interviews.

188 For estimates of Hutong residents' annual incomes, see supra note 22. 
available to Hutong residents one afternoon each week, free of charge, in order to publicize its legal reform efforts. ${ }^{189}$ Residents were willing to meet with lawyers under these circumstances, but when the program ended, so did their contact with members of the legal profession. 190

Of course, there are other economic costs associated with formal litigation that guided residents' preferences for norm-based solutionsnamely that litigation is a time-consuming and generally miserable process. After citing the prohibitive monetary costs involved, most residents we interviewed went on to explain that litigation demanded too much time and was far too mafan ("annoying" or "aggravating") to be worthwhile. Why, they asked, would they hire a lawyer, file documents in court, and initiate the lengthy litigation process when they can walk five meters across the courtyard and consult directly with their neighbors - who they will have to see several times during the course of each day anyway-or, in the worstcase scenario, call the Residents' Committee mediators, who will come resolve things for free? ${ }^{191}$

Added to these direct costs of litigation is the more general difficulty associated with learning the substantive content of legal codes. None of the residents interviewed had any knowledge of China's formal legal codes-to say nothing of access to formal legal training - and indeed many of the older residents we interviewed were illiterate. The time and effort required to gain a rudimentary understanding of the law is thus extremely high for Hutong residents, even if they are relatively well educated. ${ }^{192}$ In fact, our interviewees' collective ignorance of formal law probably reflects larger systemic realities of the Chinese developing legal environment. Several scholars have recently identified public ignorance of the law as a pervasive problem in China, even among lawyers, government officials, and political elites. ${ }^{193}$ This is perhaps not surprising, given the primacy of Communist party politics and Maoist ideology — and hence the weakness of law-in Chinese policy and administration since 1949. China's prodigious legal reform efforts since 1979, while spectacular in their own right, certainly have

189 This was reported in one of our interviews.

190 Many interviewees referred to this program with enthusiasm and interest, though very few said that it changed their view of lawyers or the law in any meaningful way.

191 This is a summary of a general consensus among interviewees.

192 In his study of Shasta County ranchers, Ellickson similarly found that formal law is disfavored because it is difficult to learn and apply. See Ellickson, supra note 80, at 686.

193 See Randall Peerenboom, Ruling the Country in Accordance with Law: Reflections on the Rule and Role of Law in Contemporary China, CULTURAL DYNAMICS, Nov. 1999, at 315, 333. 
not erased the accumulated political practices and administrative modalities of prior decades.

Yet, even for those who invest time in learning the laws of China, the current Chinese legal environment remains complex and uncertain. As part of its efforts to develop a more robust legal system, the National People's Congress passed 328 laws and decisions, the State Council promulgated 770 administrative regulations, and local legislatures enacted more than 5,200 local regulations between 1979 and 1997.194 Beyond this are more than 24,000 "legal enactments" created by executive ministries under the national State Council, ${ }^{195}$ and the massive, Byzantine nature of China's new legal code becomes apparent. As mentioned earlier, this general complexity and opacity are particularly acute in laws concerning urban housing property rights. 196

The difficulties that inhere in such volume and complexity are further exacerbated by the way Chinese laws are typically drafted. Most new statutes and regulations are set forth in intentionally broad, vague terms to allow the Chinese government maximum flexibility in its application and enforcement of official rules. ${ }^{197}$ Laws also tend to be inconsistent, ${ }^{198}$ and rules-or their method of application - often change rapidly with minimal notice. ${ }^{199}$ One Hutong resident joked that the Chinese government outlaws everything, and then decides which laws it will actually enforce based on prevailing political conditions and policy priorities: "This year it is an anti-domestic violence campaign," remarked one resident. 200 "Next year, maybe other things will be more important."201 The government constantly initiates new experimental policy programs - complete with their own sets of rules and regulationsthat are later either broadened or discontinued as administrative needs

194 Cai Dingjian, Development of the Chinese Legal System Since 1979 and Its Current Crisis and Transformation, CULTURAL DYNAMICS, July 1999, at 135, 136; see also William P. Alford, A Second Great Wall? China's Post-Cultural Revolution Project of Legal Construction, CULTURAL DYNAMICS, July 1999, at 193, 194 (corroborating these figures).

195 Alford, supra note 194, at 194.

196 For a discussion of housing property rights, see supra Part II.

197 Peerenboom, supra note 193, at 336.

198 See Peter Howard CORne, Foreign INVESTMENT IN ChINA: The ADMINISTRATIVE LEGAL SYSTEM 152 (1997) (finding that two-thirds of local laws in Beijing, Hebei, and Tianjin are inconsistent with the Chinese National Constitution).

199 Interviews with Residents, Hou Hai Hutong neighborhood, supra note 79.

$200 \mathrm{Id}$.

201 Id. 
demand. ${ }^{202}$ Along these same lines, very little historical case law is available to guide legal interpretations or enable accurate prediction as to how legal authorities will interpret certain laws or handle certain types of legal issues. ${ }^{203}$ Of course, these conditions impose great uncertainty on citizens trying to ascertain the contours of their own legal rights and duties.

Yet perhaps the greatest problem in the Chinese legal system today lies in the continued politicization of Chinese law. Despite all the aforementioned reform efforts, the CCP still effectively controls the application of law in Chinese courts. Chinese judges are still appointed by the Party; they often consult with CCP officials on how to decide difficult cases, ${ }^{204}$ and anywhere from $25 \%$ to $40 \%$ of judicial rulings go unenforced for political reasons. ${ }^{205}$ Judges have not achieved independence from the CCP's political superstructure, and, as such, litigation remains more a political than a legal exercise. ${ }^{206}$

Given all of these difficulties, it is no wonder that Hutong residents are loathe to venture into the realm of formal law when handling local disputes. The vast majority of residents do not know any of the law's Byzantine formal content, and, even if they possessed such knowledge, they could not accurately predict which rules actually would be applied to any given case. Most residents thus see calling the police or engaging the court system as a crapshoot: Complicated rules will be applied and some remedy will be mandated, but one can never predict which rules will be used or how they will be interpreted.

To precisely illustrate this point, one resident told a story-which had apparently become local legend in his neighborhood-about a resident whose pet dog was run over by a motorist. The motorist offered to pay the purchase price of the animal, which was quite low, but refused to offer any additional compensation. The irate dog owner summoned the Beijing police, only to be heavily fined for improperly registering his (now deceased) dog with the city authorities. The motorist was allowed to leave without paying anything. It

202 Peerenboom, supra note 193, at 337.

203 To the extent that it has modern legal institutions, the Chinese system is more closely related to a civil law system, with minimal emphasis on common law jurisprudence through an accretive case law.

204 Edward J. Epstein, Law and Legitimation in Post-Mao China, in DoMESTIC LAW REFORMS IN POST-MAO CHINA 41 (Pitman B. Potter ed., 1994); Stanley Lubman, Bird in a Cage: Chinese Law Reform After Twenty Years, 20 Nw. J. INT'L L. \& Bus. 383, 395-96 (2000).

205 Peerenboom, supra note 193 , at 341.

206 Stanley Lubman, Introduction: The Future of Chinese Law, in CHINA'S LEGAL REFORMS 6 (Stanley B. Lubman ed., 1996). 
was actually the dog owner's own fault, our storyteller insisted, as everyone knows that calling the police is generally a risky proposition. In a colloquial sense, the dog owner had "assumed the risk" of any adverse consequences when he involved the Beijing police in his dispute; he should have just phoned the Residents' Committee mediators. ${ }^{207}$

In fact, these deficiencies in the Chinese legal system may predate the Communist era. Some scholars have posited that the historic inaccessibility or inadequacy of the Chinese imperial court system contributed to the widespread entrenchment of private mediation traditions in Chinese society. ${ }^{208}$ Modern Hutong residents' response to these institutional shortcomings should not be surprising. Prior scholarship has demonstrated that the structure of legal regimes matters in determining how legal rules will be applied and enforced in practice. ${ }^{209}$ Individuals will predictably eschew rules and enforcement mechanisms that are ill-suited to their personal circumstances. ${ }^{210}$ Other scholars focusing on Asia generally have noted that the informal, norm-based practices of private "middlemen groups" have traditionally figured prominently in Asian commerce, especially in areas where legal institutions are deficient and legal entitlements are not reliably enforced. 211

Clearly, resorting to formal legal proceedings requires money, time, effort, and exposure to high levels of uncertainty for Hutong residents. Yet there is another less prototypical "cost" associated with formalized legal rule enforcement that may be at least as important in creating preferences for

207 Interviews with Residents, Hou Hai Hutong neighborhood, supra note 79.

208 See, e.g., Michael T. Colatrella, Jr., "Court-Performed" Mediation in the People's Republic of China: A Proposed Model to Improve the United States Federal District Courts' Mediation Programs, 15 OHIO ST. J. ON DiSP. RESOL. 391, 397-98 (2000); Justice Robert F. Utter, Dispute Resolution in China, 62 WASH. L. REV. 383, 386-87 (1987).

209 Barbara E. Koh, Alterations Needed: A Study of the Disjunction Between the Legal Scheme and Chinatown Garment Workers, 36 STAN. L. REV. 825, 854 (1984) (finding that garment workers in San Francisco's Chinatown do not benefit from their formal legal rights because they are generally socially isolated and unaware of such rights, and because legal remedies and enforcement mechanisms clash with the social realities of their employment conditions).

210 Id.

211 Robert Cooter \& Janet T. Landa, Personal Versus Impersonal Trade: The Size of Trading Groups and Contract Law, 4 INT'L REV. L. \& ECON. 15, 21 (1984). 
norm-based solutions: social costs..$^{212}$ Initiating lawsuits or calling the police are seen as extremely hostile, anti-social acts among Hutong residents. ${ }^{213}$ No matter how compelling one's claim against a neighbor, in the eyes of the community, summoning public authorities implies a distrust of the neighborhood social network and the private solutions it is able to deliver. Since residents live in such close proximity, the inconvenience and stress associated with government intervention are generally shared to some degree, especially among neighbors who share a common courtyard space. As mentioned earlier, all of our 65 interviewees expressed an aversion to lawsuits or police intervention in general, and many made a point of saying that they would never want to create such a neighborhood-level disturbance unilaterally. This attitude echoes the old Chinese adage recited by one elderly interviewee: "It is better to starve to death than become a thief. It is better to be vexed to death than to bring a lawsuit."214

There was also general agreement among residents that initiating legal proceedings or calling the police constitutes a public expression of contempt for the opposing party and his or her reputation. Such an affront is likely to effectively terminate any ongoing social relationship and guarantee the complainant a lifelong enemy, whatever the outcome of the lawsuit or intervention. Again, in light of the close physical proximity of most Hutong households, and the high frequency of interaction between neighbors, it is extremely problematic to make enemies of nearby residents. ${ }^{215}$ As Ellickson found in his study of Shasta County ranchers, most neighborly disputes represent mere "minor irritations between parties who typically have complex continuing relationships." 216 These ongoing relationships enable residents to enforce their own norm-based regimes informally ${ }^{217}$ and are threatened by recourse to formal litigation. Enter another proverb (also

212 Cf. West, supra note 4, at 304 (finding that "social factors" often drive Japanese citizens to employ institutionalized norm-based mechanisms rather than formal litigation when resolving Karaoke noise disputes).

213 Cf. Ellickson, supra note 80, at 681 (finding that ranchers in Shasta County, California view filing a lawsuit as a hostile social act).

214 This was reported in one of our interviews.

215 For detail on the exigencies of informal sanctions and reprisals between neighbors, see our discussion of enforcement mechanisms in Hutong communities infra Part VII.

216 Ellickson, supra note 80, at 628.

217 Id.; see also infra Part VII (discussing norm-based resolutions in Hutongs). 
referenced in one of our interviews): "It is better to keep a friend than to win a litigation." 218

While most of us can readily imagine the adverse social effects of litigation in a small community, theoretical approaches can help place such phenomena more squarely within a generalized cost-benefit calculus. Specifically, Robert Putnam's concept of social capital-'features of social organization, such as networks, norms, and trust, that facilitate coordination and cooperation for mutual benefit"-may be informative. ${ }^{219}$ Given the close physical proximity of households and the frequent interactions between neighbors, it may be fairly said that Hutong communities produce, and in turn depend on, large amounts of social capital. In particular, "bonding" social capital (Putnam's "sociological superglue"), which creates bonds among members of discrete groups and "is good for undergirding specific reciprocity and mobilizing solidarity," 220 is of great value to most Hutong residents. As Putnam elucidates, this value is not simply emotive: "Social norms and the networks that enforce them" help communities overcome collective action problems, reduce the uncertainty and transactions costs associated with interactions between strangers, facilitate information exchange, and make for more public-regarding citizens. ${ }^{221}$

Such benefits are of particular importance in communities, like Hutongs, where residents must interact frequently and often depend on one another in performing the basic tasks of everyday life. Hutong residents generally must share common courtyard bathrooms, obtain water from common courtyard taps, and share basic household implements, such as tools, gardening equipment, and large cooking appliances. Kitchen facilities tend to be located in common courtyard space (for ventilation reasons), and all families share responsibility for keeping common areas clean. Responsibility for collection of water, electricity, maintenance, and sanitation payments typically rotates among the households in a given courtyard, with a new family assuming collection duty every one to six months. Similarly, child rearing and care for

218 Interview with Resident Group, Jianguomen Wai Hutong neighborhood, supra note 35 .

219 For Putnam's explanation of this influential concept, see ROBERT D. PUTNAM, Bowling Alone: The CollaPSE AND Revival of AMERICAN COMMUNITY 21-24, 65-67 (2000).
$220 \mathrm{Id}$. at 23.
221 Id. at $288-89$. 
the elderly are often largely communal activities, shared by groups of households as their needs and abilities dictate. 222

Given these extensive interdependencies, fear of litigation's social consequences reflects not just an emotional aversion to unpleasant interpersonal relations, but rather a subtle understanding of the community's social fabric and its exigencies. By creating discord, distrust, and enmity, recourse to formal legal channels depletes the pool of social capital on which the whole community depends. Private negotiation or informal mediation, on the other hand, is more conducive to individual engagement, relationshipbuilding, and maintenance of shared community values ${ }^{223}$-in other words, they are conducive to the creation and preservation of social capital. To the extent that social capital is tied to the economic prosperity of communities, as Putnam contends, 224 destruction of social capital may be considered a "cost" of law-based dispute resolution in the traditional economic sense. Once the centrality of solid social networks to Hutong communities is recognized, the social disruption associated with litigation or other law-based solutions can be considered a legitimate component of residents' cost-benefit calculus, even if it remains completely non-monetized. ${ }^{225}$

One additional factor that deserves mention is cultural tradition. While purely cultural explanations of dispute resolution phenomena are generally too vague and deterministic to be satisfying, it is nonetheless clear that "the way societies handle disputes is culturally constructed" to some degree.226 Here, it is sufficient merely to note that voluntary mediation mechanisms

222 For a more complete discussion of Hutong living conditions, see supra Part II.B (discussing Hutongs as residential environments).

223 Colatrella, supra note 208, at 392-93; see also Robert A. Baruch Bush, What Do We Need a Mediator For?: Mediation's "Value-Added" for Negotiators, 12 Oнlо ST. J. ON DISP. RESOL. 1, 27 (1996); Carrie Menkel-Meadow, When Dispute Resolution Begets Disputes of Its Own: Conflicts Among Dispute Professionals, 44 UCLA L. REV. 1871, 1872 (1997). Mediation in particular has been found to foster individual "empowerment" and enhanced "recognition" (or empathy for other parties) - qualities which would seem naturally conducive to the formation of social capital. See ROBERT A. BARUCH BUSH \& Joseph P. Folger, The Promise of Mediation: Responding to Conflict Through EMPOWERMENT AND RECOGNITION 84-95 (1994).

224 PUTNAM, supra note 219, at 319-25.

225 Mark West has also found that decisions to eschew formal legal dispute resolution mechanisms in favor of less formal norm-based mechanisms are often driven by efforts to preserve social capital. See West, supra note 4, at 304.

226 Christine B. Harrington \& Sally Engle Merry, Ideological Production: The Making of Community Mediation, 22 LAW \& SOC'Y REV. 709, 731 (1988). 
have historically been an integral part of China's formal legal system. ${ }^{227}$ In the words of one scholar, the "Chinese legal system has been one of the world's most committed institutions in the use of mediation to resolve disputes and a leader in developing ways to maximize its benefits and effectiveness." 228 In fact, prior studies have found that more than half of all civil and economic matters filed in Chinese courts are resolved through mediation rather than formal adjudication. ${ }^{229}$ In this sense, Chinese citizens may not view Residents' Committee mediations as "extralegal" at all. Despite a lack of set procedures or written rules, such mediations are in line with longstanding practices of the formal Chinese legal system-the rulefocused and proceduralist biases of Western observers notwithstanding. Thus, historical practice and distinct cultural understandings of law and legalism probably also play some role in leading Hutong residents to prefer private mediation over formal litigation. 230

Our findings dovetail with the general proposition that, in any legal jurisdiction, legal institutions must be mindful of the transactions costs they impose on citizens, since people will resort to private solutions if the costs of using public law are too high. ${ }^{231}$ Indeed, in his groundbreaking study of cattle trespass disputes in Shasta County, Robert Ellickson found that formal law does not affect individual entitlements precisely because the transaction costs of using formal law are too high in most cases - that is, it is usually too difficult to learn and enforce legal rules through formal institutional channels. 232

With regard to the general cost and flexibility advantages of mediation over more formal legal proceedings, our findings are also fully consistent

227 See Colatrella, supra note 208, at 394.

228 Id. at 395.

229 See Jun Ge, Mediation, Arbitration and Litigation: Dispute Resolution in the People's Republic of China, 15 UCLA PAC. BASIN L.J. 122, 128 (1996) (noting that $61.5 \%$ of all civil and economic matters filed in Chinese courts in 1986 were ultimately resolved through court-performed mediation).

${ }^{230}$ For elaboration, see discussion of the historical roots of mediation and the Residents' Committee supra Part IV.B.

231 See Ugo Mattei, Basic Principles of Property LaW: A Comparative Legal AND ECONOMIC INTRODUCTION 56 (2000).

232 Ellickson, supra note 80 , at $628-29,686$. In fact, Ellickson discovered that neither the residents of Shasta County nor their insurance adjusters heeded legal distinctions in settling trespass claims. Id. at 685-86. 
with the relevant alternative dispute resolution (ADR) literature. ${ }^{233}$ The impetus for many ADR programs often lies in the lower time and money costs of mediation compared with litigation, as well as the greater degree to which mediated outcomes can be tailored to the unique exigencies of individual disputes or the preferences of specific disputants. ${ }^{234}$ Scholars focusing on China specifically have expounded on the enduring appeal of "court performed" mediation as a "flexible process that is tailorable to a variety of disputes." 235

Hutong residents' aversion to formal law thus becomes fully comprehensible, once the relative costliness of legal solutions-along both monetary and social dimensions-is considered. Formal law is generally eschewed primarily because it requires too much time, money, and uncertainty, and it damages vital social relationships.

\section{B. Where Social Ties End: The Domain of Formal Rules (and Law) in Hutong Life}

All of this is not to say that formal law is never used in Hutong residents' dispute resolution. Under circumstances where disputes are extremely serious, the injuries or losses involved are catastrophic, or where incentives to preserve ongoing social relationships no longer exist, formal law may be used to resolve conflicts. Specifically, interviewees consistently reported that recourse to formal legal channels is more likely in cases involving physical fights, serious injuries, large-scale property destruction, and divorce or final division of household property. ${ }^{236}$ In many of these cases, residents' use of formal law may simply reflect the fact that the traditional economic costs of doing so are overcome by the injuries - or potential injuries-involved. If, for example, a residence burns to the ground, a resident is severely injured in an altercation, or all of one household's property must be divided, the time and money costs of litigation may become justified in purely monetary terms.

233 See Wayne D. Brazil, Why Should Courts Offer Nonbinding ADR Services?, 16 ALternAtIVES TO HIGH COST LITIG. 65, 74 (1998); Steven Shavell, Alternative Dispute Resolution: An Economic Analysis, 24 J. LeGAL STUD. 1, 1-4 (1995).

234 Id.

235 Colatrella, supra note 208, at 392-93.

236 Residents consistently offered these four types of disputes, or subsets of them, when asked the following open-ended question: "What kinds of disputes require recourse to formal law?" Physical altercations appeared to be the prototypical example, as 27 of 35 residents in one interview set (over $77 \%$ ) mentioned this category specifically. 
On a more fundamental level, all of these more serious dispute categories also represent "end game" situations-situations where preexisting relationships, and the associated promise of iterated future interactions, are either destroyed or significantly devalued. Lisa Bernstein and others have noted the significance of end-game situations in dispute resolution: While informal norms and the exigencies of ongoing relationships may be the most efficient drivers of dispute resolution at mid-game, formal rules and institutions are often needed to resolve disputes when relationships-and associated incentives to preserve community norms and find mutually acceptable solutions-end. ${ }^{237}$ Accordingly, several studies have found that litigation generally occurs between strangers or where existing relationships have already "ruptured." 238 Indeed, in many cases the litigation itself acts to end preexisting relationships. ${ }^{239}$ Divorce is one paradigmatic example of this, as a prior marital relationship is formally terminated. Indeed, residents report that, as more robust legal institutions have developed in recent years, divorcing couples have increasingly sought professional legal advice about property division and custody issues. 240

Of course, termination of ongoing relationships need not be formalized. In cases of physical fights or serious injuries, for example, the enmity and illwill naturally generated by such events may effectively end the parties' interest in a continuing social relationship. Our interviews revealed that residents almost universally call the police when serious physical altercations erupt. ${ }^{241}$ In some cases, the police may be called by a concerned neighbor who, while not directly involved in the fight, fears the impact of violence on the social milieu of the neighborhood (or courtyard) in general. Still, even in cases of physical violence or serious injuries, informal mediation can prove relevant. In one interesting case, a motorist accidentally ran into a small shack in a Hutong alleyway, which fell onto an elderly woman sitting nearby, seriously injuring her. ${ }^{242}$ Though the woman's family initially sought to sue

237 See Bernstein, supra note 182, at 1766-71 (discussing norms versus institutions in the context of merchant law).

238 See id.; Ellickson, supra note 80, at 672-78; Marc Galanter, Reading the Landscape of Disputes, 31 UCLA L. REV. 4, 24-25 (1983).

239 See Galanter, supra note 238, at 24-25.

240 Interview with Resident Group, Liu Li Chang Hutong neighborhood (June 30, 2002) (notes on file with authors); Interview with Resident Group, Yabao Lu Hutong neighborhood, supra note 129.

241 See supra note 236 (comments by residents on the use of law enforcement in the context of physical altercations).

242 Interview with Resident Group, Liu Li Chang Hutong neighborhood, supra note 240. The woman's family called the police and consulted with the relevant legal 
the motorist for damages, the parties eventually agreed on a private resolution, mediated by the police and representatives from the Residents' Committee, which actually contravened the relevant Chinese law by excluding the motorist's work unit ("danwei") from the negotiations and the payment of damages. ${ }^{243}$

There is one other area of Hutong life where formal rules tend to hold sway, and it too is an area where social relationships between residents lose much of their importance: the provision of utilities and other public goods. Maintenance and repair of public property at the alleyway level (such as street lights), garbage collection, and the provision of water and electricity are all governed by formal legal rules or fixed government policies. ${ }^{244}$ In many cases, this is simply driven by formidable collective action problems and resource availability. Collection of waste, operation of a water-supply system, and maintenance of a large-scale electrical grid are most efficiently handled by government public works projects in China as in most societies. Individual neighborhoods simply do not have the means to serve these functions efficiently by themselves.

Yet even here, social relationships and community norms can be relevant where technology, or lack thereof, demands. For example, each Hutong household has its own electricity meter, so electricity bills are easy to calculate according to standard government-set rates for power usage. ${ }^{245}$ Hutong households generally do not have individual water meters; typically,

authorities, fully intending to bring a lawsuit to recover damages. However, after repeated meetings with the motorist at the hospital where the woman was being treated, the woman's family agreed to reach a private agreement with the motorist instead of resorting to formal court proceedings. The motorist agreed to pay all the woman's hospital bills and the subsequent costs of medication and ongoing medical care. He also agreed to pay the woman's family for their lost wages due to time spent at the hospital and for emotional suffering. The motorist, the local police, the victim's family, and a community representative from the Residents' Committee met several times throughout this process to agree on the amount of the damage payments. These elaborate negotiations were conducted completely outside the formal legal system, despite the presence of police officers in the negotiations. In fact, according to the police officers involved, formal Chinese law would have required the motorist's work unit ("danwei") to be involved in making damage payments, but the parties' private negotiations bypassed this requirement altogether. $I d$.

243 Id.

${ }^{244}$ Id; ; Interview with Residents' Committee, Jianguomen Wai District, supra note 22.

245 Interview with Resident Group, Liu Li Chang Hutong neighborhood, supra note 240; Interview with Residents' Committee, Jianguomen Wai District, supra note 22. 
each courtyard has one communal water source with its own central meter. ${ }^{246}$ Thus, the households of each courtyard are charged collectively for monthly water use, and they are left to their own devices to divide these costs among households. ${ }^{247}$ An informal norm has arisen whereby courtyard water bills are divided by the number of people in the courtyard with each household contributing money according to the number of its members. ${ }^{248}$ In other words, while technological advancements have insulated payment of electrical bills from the contingencies of social relationships, a lack of similar technology in water provision ensures the continued relevance of community networks and social norms.

Of course, this is in line with our more general findings concerning the role of formal rules at endgame: Technology has effectively rendered all ongoing social relationships irrelevant to payment of electricity costs. By contrast, allocation of water costs is a highly social exercise, and disputes have predictably arisen over certain households' alleged "stealing" of water from their neighbors. ${ }^{249}$ According to our interviews, most of these disputes concern the classification of infants or small children as "members" of households for cost allocation purposes, or the duty of households to pay extra for guests who stay with them for extended periods of time. ${ }^{250}$ The residents' committee members we interviewed reported handling water disputes on a regular basis, adhering to the per capita allocation norm where feasible.

Clearly, the meter-based allocation of electricity costs is more straightforward and definitive than the per capita calculus used for water bills. While heightened legal formality and greater clarity coincide in this case, it is the metering technology, not the formal rules per se, that creates this certainty. As China's economy further develops and modernizes in the future, technological advancements will certainly have their effects, perhaps removing other areas of Hutong life from the social domain and allowing for the use of more truly "mechanized" rules. Whether this contingency is normatively desirable or not is a question worth considering, though ultimately beyond the scope of this paper.

246 See supra note 245.

247 Id.

248 Id.

249 Id.

250 Interview with Resident Group, Liu Li Chang Hutong neighborhood, supra note 240. Such issues were also reported for electricity costs where individual household meters were broken or costs were tracked by both household and communal meters (which often registered different totals). $I d$. 
In sum, Hutong residents employ formal rules primarily where the stakes are large or where the relevance of their social relationships end, whether by dint of socially catastrophic disputes, the formal termination of habitation or familial relationships, or the exigencies of new technology.

\section{Predictability, Best Practices, and Socially Constructive "Voice": The Advantages of Mediated Solutions}

Our research thus clearly confirms the primacy of informal norms in dispute resolution among members of a cohesive community. Hutong communities are paradigmatic examples of Robert Ellickson's "close-knit" group: "a social network whose members have credible and reciprocal prospects for the application of power against one another and a good supply of information on past and present internal events." 251 And, as in the closeknit groups examined by Ellickson and others in the literature, norms-rather than formal law-tend to dominate dispute resolution systems. Additionally, while confirming the cost advantages and flexibility associated with normbased solutions in general, and mediation in particular, our field research also suggests that, especially in the context of a developing legal system, normbased mediation may offer disputants greater certainty, clarity, and predictability than either formal legal solutions or private norm-based bargaining between neighbors.

Prior scholarship has tended to contrast the different comparative advantages of bright-line rules and broad general principles within legal systems. ${ }^{252}$ In China, it is formal law that is unpredictable and "muddy," due chiefly to its highly politicized method of application and its general lack of precision or standardization. ${ }^{253}$ Conversely, since the social principles that govern Residents' Committee mediations are widely shared within Hutong communities, residents testified that such mediations in fact offer substantial levels of clarity and predictability. Universal norms against fighting, disruptive uses of courtyard space, damaging the property of others without offering compensation, free-riding on the common water supply, and demanding payment from the destitute narrow the range of socially legitimate resolutions to any given dispute, thereby providing Hutong mediations with some of the predictability normally associated with brightline rules, while simultaneously preserving the essential flexibility of

251 ELLICKSON, supra note 1, at 181.

252 See Carol M. Rose, Crystals and Mud in Property Law, 40 STAN. L. REV. 57790 (1988).

253 See supra Part VI.A (discussing the Chinese legal regime). 
principle-based systems. As one scholar noted, when disputes arise in small communities "norms allocate risks and specify means of resolution," 254 and this may provide at least as much predictability and clarity as the provisions of an institutionally deficient legal system.

This clarity is enhanced where norm-based mediations are performed by known members of the Residents' Committee according to reasonably standardized, if still informal, procedures. Residents generally are familiar with their Residents' Committee representatives (indeed they voted them into office), and the outcomes of past mediations often provide some guidance as to how future disputes may be handled. Unlike one-off private negotiations between parties, more centralized mediating authorities are able to aggregate and disseminate-formally or informally-information about mediation outcomes and standardize practices over time. In this way, the activities of non-legalistic public authorities, while not based on any codified rules, may provide residents with a kind of norm-based folk case law system. Residents often are able to predict future outcomes with some level of certainty based simply on the identity of the mediator involved and information about outcomes of past disputes. 255

Beyond providing enhanced predictability and clarity, mediation through non-legalistic public authorities may provide the additional advantage of mitigating the costs associated with private negotiations in situations of bilateral monopoly. Several theorists have demonstrated that negotiations within bilateral monopolies-situations where two parties each have unilateral power to preclude resolution of a given dispute-tend to be costly, as individuals have incentives to be strategic and non-conciliatory. ${ }^{256}$ Intervention by non-legalistic public authorities like the Residents'

254 Eric A. Posner, The Regulation of Groups: The Influence of Legal and Nonlegal Sanctions on Collective Action, 63 U. CHI. L. REV. 133, 155 (1996) ("When members of a solitary group transact, norms and non legal sanctions generally resolve disputes. When contingencies arise, norms allocate risks and specify means of resolution. Norms also prohibit bad faith and opportunism. The importance of maintaining a good reputation and of avoiding ostracism deters improper behavior.").

255 Interview with Resident Group, Liu Li Chang Hutong neighborhood, supra note 240.

256 See Robert Cooter et al., Bargaining in the Shadow of the Law: A Testable Model of Strategic Behavior, 11 J. LEGAL STUD. 225, 243 (1982) ("[P]eople will exercise their worst threats against each other unless there is a third party to coerce both of them."); William A. Landes \& Richard A. Posner, Salvors, Finders, Good Samaritans, and Other Rescuers: An Economic Study of Law and Altruism, 7 J. LEGAL STUD. 83, 91 (1978) ("[T]ransaction costs under bilateral monopoly are high."); see also RICHARD A. POSNER, ECONOMIC ANALYSIS OF LAW 45 (2d ed. 1977). 
Committee may serve to soften these difficulties, and community interests are introduced to temper the private strategic interests of the individual parties.

Albert Hirschman has famously posited that individuals generally resort to "exit" (removing oneself from the situation entirely) or "voice" (making one's grievance known) when faced with an unacceptable situation. ${ }^{257}$ In the context of a Hutong residential environment, most disputants cannot simply "exit" the community or escape interactions with their neighbors-the Beijing housing market is tightly regulated, most residents do not have enough money to purchase property elsewhere, and the threat of impending government demolition of Hutong areas generally makes Hutong residences hard to sell. ${ }^{258}$ Under these circumstances, exercise of "voice" is often the sole option available to disgruntled residents, and as such it must be carefully managed and channeled into socially constructive modes. Again, as unofficial stewards of the community interest, Residents' Committee mediators are well positioned to exercise "voice." Resort to third-party mediation often avoids the destructive escalation of disputes through individual reprisals or, in the extreme, vigilantism, and ensures that resident "voice" will be exercised in a socially constructive manner. In fact, several residents we interviewed reported that individuals often call for Residents' Committee intervention precisely because they do not want to deal solely with the opposing party in discussing a grievance. ${ }^{259}$ Rather than confronting one's neighbors in a socially awkward bilateral confrontation, third-party mediation often promised more productive and less socially painful outcomes.

Finally, to the extent that "social capital ... underwrites the successful enforcement of formal state policy," 260 as some have suggested, use of normbased dispute resolution mechanisms, where feasible, may actually augment the effectiveness of formal legal regimes by bolstering the social cohesion necessary for the effective functioning of any legal system. Indeed, Robert Cooter has postulated that formal laws are most needed in cases of norm

257 Albert O. HiRSCHMAN, EXIT, VOICE, AND LOYALTY: RESPONSES TO DECLINE IN FIRMS, ORGANIZATIONS, AND STATES 4 (1970).

258 See supra Parts II.A, II.C (discussing recent Chinese government policies and their implications for the future of Hutong neighborhoods).

259 One example of the phenomenon is the pigeon defecation dispute, where the complainants first consulted the Residents' Committee because they were uncomfortable confronting their neighbor directly about the problem. See supra Part V.

260 Richard H. Pildes, The Destruction of Social Capital Through Law, 144 U. PA. L. REV. 2055, 2076 (1996). 
"market" failure. ${ }^{261}$ Where organic social processes create dysfunctional or inefficient social practices, formal law can serve a corrective function by enforcing a more efficient norm or creating new, socially useful legal obligations. ${ }^{262}$ Where organic social norms are functioning well, however, government imposition of formal legal rules may be unnecessary or, at worst, damaging to the social fabric of the community. ${ }^{263}$

Of course, private negotiations between residents can adequately serve to reinforce social norms, but there is always a danger that private parties will implement dysfunctional or socially destructive norms. Specifically, parties may make arrangements that impose serious externalities on other members of the community. ${ }^{264}$ Resort to third-party mediation is certainly not a failsafe solution to this dilemma, but, as specialized mediators typically intervene in numerous disputes over time, they can aggregate information and identify best practices, much as common law judges might. In this capacity, they can reduce the "inevitable tension between dispute resolution's private function and its public function." 265 Non-legalistic public authorities thus not only reinforce the vitality of social norms writ large, their special role as repeat mediation players positions them to (ideally) reinforce the right norms - those that will ultimately contribute to a healthy legal system more generally. 266

By way of summary, the close physical proximity of Hutong neighbors and the myriad of social ties that typically bind them, combined with a desirable lack of formalized procedure, make private neighbor-to-neighbor bargaining an extremely cheap dispute resolution method. There are no lawyer's fees to pay, no time spent in court, and transaction costs tend to be very low, as it is logistically easy to find the other party in question, conduct

261 Robert Cooter, Normative Failure Theory of Law, 82 CORNELL L. REV. 947, 948-49 (1997).

262 Id.

263 See Pildes, supra note 260, at 2057, 2077; see also supra Part VIII (discussing the implications of our findings for broader Chinese legal reform efforts).

264 See ElLICKSON, supra note 1, at 169 (noting that organic social norms may create benefits for a given community at the expense of other groups).

265 See Menkel-Meadow, supra note 223, at 1873 (discussing the inevitable tensions that can arise).

$266 \mathrm{~W}$. Bradley Wendel has noted that "there is no guarantee in the concept of a community that the community's norms will be those that ethically ought to be endorsed. Unless informal social norms are kept in check by extra-community criticism, nothing prevents the community's values from moving toward vice instead of virtue." W. Bradley Wendel, Nonlegal Regulation of the Legal Profession: Social Norms in Professional Communities, 54 VAND. L. REV. 1955, 1968 (2001). 
negotiations, and monitor compliance with an agreed-upon solution. ${ }^{267}$ As such, this most informal first-tier method was the one most commonly used by the residents interviewed, and was associated with simple high-frequency, low-severity disputes that do not fundamentally threaten ongoing social relationships or implicate the interests of the community. ${ }^{268}$

As might be expected, more formal mediation by a Neighborhood Police officer or a Residents' Committee mediator ${ }^{269}$ involves significantly higher transaction costs for the parties than informal negotiation. Furthermore, resort to these "second-tier" options necessarily connotes a level of enmity and social discord not present in informal neighbor-to-neighbor negotiations. Intervention by the Residents' Committee and the Neighborhood Police are thus associated with less frequent disputes that are too serious for neighborto-neighbor resolution but do not threaten the fundamental social fabric of the community. In second-tier situations, neighborly relations are tense but salvageable, and a neutral mediator acting as the "voice of the community" can play a useful role in defining individual entitlements and affirming common values. ${ }^{270}$

Resort to formal third-tier legal channels-official legal institutions like the police and the courts-typically is reserved for extremely serious or intractable disputes that involve extremely large stakes, terminate ongoing

267 Predictably, the high costs of conducting negotiations in situations of bilateral monopoly can be a factor here. See supra Part VI (discussion of cost-benefit analysis involved in choosing a dispute resolution method).

268 Minor property damage and mildly annoying use of common courtyard space (such as playing loud music or cluttering common areas) are prototypical examples. All of the more than 60 residents interviewed reported using informal negotiations as a default first option in all but the most serious, intractable disputes. In the final analysis, it is almost always socially easier and economically cheaper to approach neighbors individually and discuss a grievance privately. Id. (discussing residents' cost-benefit calculus in choosing dispute resolution methods).

269 There is an extensive literature on the importance of third-party mediators and the tradeoffs between using truly disinterested "neutrals" versus "experts" familiar with the social, professional, or institutional context of the dispute. See Menkel-Meadow, supra note 223 , at $1882-84$.

270 The disputes brought to the Residents' Committee were myriad and varied, including significant property damage, prolonged and unusually obnoxious use of common space, disputes over the allocation of water costs (which are assessed separately for each courtyard), or disputes over debts or minor damage payments. See, e.g., supra text accompanying notes 91-92. 
relationships, threaten the basic social fabric of the community and implicate important public interests. 271

\section{MAKING MEdiated SOlutions STICK: REPRISAls, STATUS, SHAME, GIFTS, AND OTHER INFORMAL SOCIAL ENFORCEMENT MECHANISMS}

Of course, no dispute resolution regime is of much use if it generates solutions that are difficult to enforce or commonly disregarded by disputants. Accordingly, the enforcement imperative was a recurring topic in our field research interviews. As mentioned earlier, the Hutong Residents' Committees have no formal powers of coercion; they cannot impose fines or formal penalties of any kind on residents. ${ }^{272}$ While the Residents' Committee could summon the municipal police-or some other public actor-to preserve public order in a particularly extreme case, so too could the average Hutong resident. And, in any event, the Beijing police are not in the business of enforcing resolutions mediated by local Residents' Committees. But what is striking is how seldom recourse to state power is actually used once the Residents' Committee decides to mediate a dispute. Of our 65 research interviews with residents, only five $(8.125 \%)$ reported incidents of a Residents' Committee failure to affect a viable resolution once mediation was initiated. ${ }^{273}$ Aside from the types of cases normally handled through formal legal channels -incidents of serious physical violence, dissolution of households and final division of property274_-Residents' Committee mediation appears to be extremely effective in resolving disputes, and the mediated solutions tend to stick.

In the absence of any formal coercive power, Residents' Committees' ability to enforce mediated resolutions rests entirely on (1) their moral authority as articulators of community values and stewards of the community interest, and (2) their ability to mobilize, implicitly or explicitly, private

271 Examples from our field research include large-scale property destruction, division of property upon divorce, or physical confrontations involving serious injuries.

272 See supra Part II (discussing Residents' Committees).

273 These cases involved either intra-family disputes (three) or physical altercations (two). This does not include disputes where mediations were ongoing at the time of the interview. Residents seemed to have a good sense of their Residents' Committee's mediation capacity, as most of them reported that for extremely serious disputes (e.g., serious injuries or physical violence), they would bypass the Committee and call the police immediately. This could partially account for the Committees' high success rate.

274 See supra Part VI (discussing when Hutong residents typically invoke formal legal channels). 
residents to enforce mediated resolutions through informal social sanctioning. Scholars have discovered that, as a general matter, "informal" or "second-order" social sanctions (like public shaming) can powerfully shape individual incentives and facilitate the enforcement of shared social norms. ${ }^{275}$ This is especially so in Ellickson's "close-knit" groups mentioned earlier. ${ }^{276}$ In communities with strong, extensive intra-group social bonds, members have a greater ability to monitor the implementation of norm-based dispute resolutions and more points of contact at which to apply social sanctions against intransigents. Ellickson's insight dovetails with Putnam's construct of "bonding social capital," the "sociological superglue" that binds tight-knit communities together, "undergirding specific reciprocity and mobilizing solidarity" through complex webs of social relationships. ${ }^{277}$

Such conditions are certainly present in Hutong communities generally, and they apply in spades to the small mini-communities of households that share common courtyard space-these are "close-knit" groups par excellence. Hutong residents, living in such close proximity to one another, typically have-indeed typically cannot avoid — extensive daily contact with neighbors that puts them in positions of mutual dependence, allows the gathering of extensive information on their neighbors' lives and enables the reciprocal application of both social rewards and punishments. Thus, in enforcing norm-based resolutions against intransigent neighbors, residents have a diverse arsenal of social ordinance at their disposal. The most basic means of norm-enforcement are private self-help measures, though often these are organized into coordinated group enforcement efforts.

Basic physical reprisals against neighbors are common, though this is rarely done through direct violence and is often symbolic or designed to impose practical difficulties on offending individuals. Examples include secretly removing bricks necessary to build unacceptable structures in common courtyard space, ${ }^{278}$ moving pet excrement from common courtyard areas to the pet owner's doorstep, 279 responding to a neighbor's noisy activities by making intrusive noise, ${ }^{280}$ and throwing dirty kitchen water at an

275 See Robert E. Scott, The Limits of Behavioral Theories of Law and Social Norms, 86 VA. L. REV. 1603, 1603-04 (2000).

276 ELLICKSON, supra note 1 , at 181 .

277 PUTNAM, supra note 219, at 22-24.

278 Interview with Resident Group, Yabao Lu Hutong neighborhood, supra note 129.

279 Id.

280 Interview with Resident Group, Jianguomen Wai Hutong neighborhood, supra note 35 . 
offending neighbor's kitchen facilities. ${ }^{281}$ We even heard reports of semiviolent reprisals against neighbors, such as applying a timely slap to a neighbor's head, but this method seemed the exception rather than the rule, apparently used primarily by senior members of the community against younger neighbors. ${ }^{282}$

These kinds of direct private reprisals are hardly unprecedented in dispute resolution literature. In his landmark study of ranching communities in Shasta County, California, Robert Ellickson observed that ranchers often enforced informal cattle trespass norms through direct physical reprisals against trespassing cattle, including "herding the offending animals to a location extremely inconvenient for their owner" or, in extreme cases, shooting them. ${ }^{283}$ In a similar vein, research by James M. Acheson has revealed that lobster fisherman in Maine enforce common resource management norms by destroying the traps of fishermen who stray into the recognized fishing areas of others. ${ }^{284}$ These kinds of physical reprisals primarily aim to impose economic costs on norm violators-costs associated with retrieving, repairing, or replacing personal assets. In this respect, the direct physical reprisals employed by Hutong residents perform a similar function. They increase the economic costs-reckoned in time, money or material-of daily life. The owner of an offending pet must clean up the excrement placed at his doorstep, the would-be builder of an offending structure must replace stolen bricks or cut his losses, the proprietor of noxious kitchen facilities must clean up the additional dirty water thrown there by neighbors.

281 Interview with Resident Group, Yabao Lu Hutong neighborhood, supra note 129.

282 Interviews with Residents, Hou Hai Hutong neighborhood, supra note 79. Acts of physical violence seemed to be universally disfavored, primarily because of their propensity to escalate into serious confrontations or family feuds causing serious injury or necessitating police intervention. We heard a few accounts of neighbors fighting physically, but usually even these disputes were ultimately resolved through private mediation brokered by Residents' Committee members, even if the police were initially summoned to stop the violence. Some of the more colorful examples of such confrontations include an individual stabbing a neighbor in the thigh during a fight over cigarettes, Interview with Resident Group, Taiping Jie Hutong neighborhood (July 3, 2002) (notes on file with authors), and an elderly man hitting a female neighbor over the head with an abacus after a dispute about coal price discounts, Interview with Resident Group, Liu Li Chang Hutong neighborhood, supra note 240. In both cases, the disputes were resolved through intervention and mediation by other neighbors or Residents' Committee members.

283 Ellickson, supra note 80 , at $678-79$.

284 JAMEs M. ACHESON, THE LOBSTER GANGS OF MAINE 48-49 (1988). 
Yet, unlike the physical self-help measures employed by cattle ranchers and lobster fishermen, physical reprisals among Hutong neighbors occur in a densely populated social environment, and so they serve an additional symbolic or shaming function. Other members of the community will inevitably notice the application of direct physical reprisals against an offending neighbor, even if they were unaware of the initial disagreement or dispute. Thus, such reprisals can be understood as socially visible acts of protest performed in the public eye. Such acts are designed not merely to impose direct economic costs on offending neighbors, but to embarrass them, shame them, or cause them to lose face before other members of the community. This practice of making demonstrative gestures of social protest in response to private grievances actually has a rich history in Chinese culture, and it clearly both implicates and reinforces traditional Chinese social imperatives of saving face and preserving the family reputation. In times past, individuals who could not collect private debts from neighbors would sometimes resort to starving themselves on their debtor's doorstep, thus publicly protesting the injustice and bringing shame on the debtor's household. Depositing pet excrement on a neighbor's welcome mat, while certainly several orders of magnitude less extreme, can be seen essentially as an act following from this same tradition.

The exigencies of shame, status, and social prestige are also directly implicated by more purely social reprisals against norm violators. Like members of almost all communities, Hutong neighbors make extensive use of negative gossip to punish intransigent or troublesome residents. ${ }^{285}$ This kind of activity is greatly facilitated by the physically and socially intimate nature of Hutong residential life. ${ }^{286}$ Neighbors typically possess great amounts of information about each other's activities, and any particular piece of negative gossip can reach most members of the community within a day by word of mouth. Individuals interviewed in the course of the project commonly reported that defying norm-based dispute resolutions was dangerous, as it subjected one's reputation to the ravages of the rumor-

285 Prior studies have concluded that gossip is a fundamental human activity common to all cultures, suggesting that love of gossip may be a universal human predisposition. See Max Gluckman, Gossip and Scandal, 4 CURRENT ANTHROPOLOGY 307, 308 (1963). Ellickson, Merry, and others have also identified the important role of negative gossip in community norm-enforcement regimes. See, e.g., Ellickson, supra note 80, at 685; Sally Engle Merry, Rethinking Gossip and Scandal, in 1 TOWARD A GENERAL THEORY OF SOCIAL CONTROL 271 (Donald Black ed., 1984).

286 For discussion of Hutongs as residential environments, see supra Part II. 
mill. ${ }^{287}$ Said one Residents' Committee representative: "In this kind of neighborhood, nothing can escape the eyes of the community." 288 When we inquired about residents' lack of privacy, one interviewee asked rhetorically: "Who doesn't know what goes on in other households?"289

Negative gossip not only creates internal stress, frustration, and shame; it also often leads to practical or logistical difficulties, as necessary dealings with neighbors can become difficult or be precluded altogether. Community members often make coordinated efforts to combine negative gossip with other purely social sanctions in order to create a more powerful and comprehensive social punishment. One common method, colorfully described as "liangzhe" (literally: putting someone out to cool, like a hot food dish), involves collectively enforcing a community-wide social boycott of the individual and his or her family. ${ }^{290}$ This community-imposed "silent treatment" is apparently a common sanction for breaches of group norms or Residents' Committee-mediated dispute resolutions. ${ }^{291}$ Many residents seemed genuinely surprised at our suggestion that individuals might defy community norms in the absence of coercive state penalties. When asked to explain what makes norm-based mediations enforceable, one resident simply stated: "People don't want the whole neighborhood against them, so they obey."292

Yet, in addition to creating unpleasant social consequences for offending individuals, gossip can also serve as an informal way of "adjudicating" disputes and "refin[ing] the content of norms to resolve specific concerns." 293 By gossiping among themselves and agreeing to impose certain social penalties on others, community members can effectively reaffirm both

287 Almost all out interviewees reported a general lack of social privacy and pervasive sharing of gossip among neighbors. Young people in particular lamented the fact that their dating life was a constant subject of community interest and conversation.

288 Interview with Residents' Committee, Jianguomen Wai District, supra note 22.

289 Interview with Resident Group, Yabao Lu Hutong neighborhood, supra note 129.

290 Id.

291 Id.

292 Interviews with Residents, Hou Hai Hutong neighborhood, supra note 79.

293 Richard H. McAdams, Groups, Norms, Gossip, and Blackmail, 144 U. PA. L. REV. 2237, 2256 (1996). Some scholars have even asserted that the dynamics of social gossip are not conceptually far removed from those of courtroom proceedings. See Barbara Yngvesson, The Reasonable Man and the Unreasonable Gossip: On the Flexibility of (Legal) Concepts and the Elasticity of (Legal) Time, in CRossEXAMINATIONS: ESSAYS IN MEMORY OF MAX GLUCKMAN 133, 134 (P.H. Gulliver ed., 1978). 
the substantive content of shared norms and their collective commitment to them. Such activity is the very stuff of Putnam's "bonding social capital,"294 and it should come as no surprise that it is a fundamental element of the Hutong social environment. The Residents' Committees, in applying accepted community norms to neighborly disputes, can count on informal individual or communal sanctioning to enforce their mediated resolutions. In adhering to group norms, the Residents' Committees both ensure the enforceability of their resolutions and reinforce communal commitment to those norms. Private community members and Residents' Committees thus exercise a kind of joint stewardship of group norms. The Residents' Committee acts as the formal articulator and executor of norms as applied to given disputes, and the members of the community refine and affirm those norms through their own individual or collective efforts to enforce them-or the mediated solutions they dictate.

Interestingly, the Residents' Committees have another semi-official role in establishing the community social status hierarchy. Every year, the city's several district governments give awards to model households ("wu hao jiating") based on the recommendations of neighborhood Residents' Committees. 295 Among the criteria for the award are being a "good neighbor" ("hao linju") and not causing trouble in the community. 296 Households receiving the award can clearly display their "model household" status by placing an official "wu hao jiating" plaque on their door, and they also receive prizes from the district government, such as family-sized bottles of shampoo or other household goods. ${ }^{297}$ Conversely, failure to receive the award can damage the family reputation and serve as another means of informal social shaming, particularly in communities where a majority of households receive the award. ${ }^{298}$ Admittedly some residents were somewhat cynical about the award and the Residents' Committees' role in nominating households, yet the award's function as a status marker is striking, as are its explicit ties to community dispute resolution norms and institutions.

There is yet another overlay to the enforcement process, separate from norm-based private sanctioning or self-help, that deserves mention: Hutong

294 See PUTNAM, supra note 219, at 22-24.

295 This was reported in one of our interviews.

296 Id.

297 Id.

298 Id. We were told that, in some areas, a vast majority of households receive the award, creating a clear way to identify the few especially troublesome members of the community. Id. 
residents' internalized sense of community and reciprocity. ${ }^{299}$ The average Hutong residents' many ties to other members of the community-including the Residents' Committee itself-create opportunities for mutual gift exchange and the establishment of reciprocal obligations. ${ }^{300}$ The community at large, and the Residents' Committees specifically, often provide valuable assistance to individual residents. ${ }^{301}$ Beyond mediating disputes, the Residents' Committee will use its small discretionary budget to provide funds for elderly residents without children, disabled individuals, the jobless, and the indigent. ${ }^{302}$ The Committees also help families in financial trouble by bringing them food or household goods, organize social activities for the community, and hold classes or meetings on issues of common concern. ${ }^{303}$ Additionally, the close-knit, communal nature of Hutong living makes residents dependent on each other in many areas of everyday life. ${ }^{304}$ One resident remarked that, with everyone living in such close physical and social proximity, everyday problems for individual residents are really seen as communal problems; the community helps its members to get by, and so members feel a reciprocal obligation to help others and respect community norms. ${ }^{305}$

The dynamics of these internalized responsibilities and obligations do not depend on utopian notions of social harmony or public virtue. As Marcel Mauss and others have observed, gift exchange and ideas of reciprocal obligation are foundational to the ordering of human societies. ${ }^{306}$ Along similar lines, the exigencies of ongoing social relationships dictate that consideration of the overall balance of interactions typically takes precedence over the desire to gain advantage in any given transaction among members of close-knit communities. ${ }^{307}$ Thus, parties will commonly temper their attempts to prevail in individual disputes with efforts to preserve social 282.

299 Interview with Resident Group, Taiping Jie Hutong neighborhood, supra note 300 Id.

$301 \mathrm{Id}$.

302 Id.

303 Interview with Resident Group, Qianmen Hutong neighborhood (June 28, 2002) (notes on file with authors).

304 Communal child rearing and collective care for the elderly are typical examples. See supra Part II (discussing Hutongs as residential environments).

305 Interviews with Residents, Hou Hai Hutong neighborhood, supra note 79.

306 MARCELl MAUSS, THE GIFT 63-81 (1954).

307 See OlIVER WILLIAMSON, MARKETS AND HIERARCHIES 256-57 (1975). 
harmony and an overall balance in social "accounts." 308 Once again, the close-knit nature of Hutong communities makes these universal social forces especially salient. Residents are hesitant to defy the community will, not only due to pragmatic concerns about the economic and social costs of informal sanctioning, but also simply because they feel indebted to the community and thus obliged to uphold its basic norms. To the extent that Residents' Committees are identified as the legitimate stewards of the community will - and our research gives every reason to believe that they often are- this sense of obligation will extend to Committee-mediated dispute resolutions as well. ${ }^{309}$ This sense of social obligation also helps mobilize community members to impose informal sanctions on their neighbors when necessary. ${ }^{310}$

Three deterrents - none of them rooted in formal legal sanctions or state power-thus combine to uphold community norms and enforce Residents' Committee-mediated dispute resolutions in Beijing Hutongs. First, direct physical reprisals against offending individuals impose substantial economic costs. Second, community social exclusion ("putting people out to cool"), negative gossip, and the symbolic aspects of direct physical reprisals (enabled by the dense social context within which self-help occurs), impose public shame, status reduction, and other social costs on intransigents. Finally, residents' own internalized sense of obligation to the community and its norms both deter offenders from defying norm-based resolutions and lead other community members to enforce norm-based dispute resolutions through direct reprisals against offending neighbors.

In light of this layering of deterrents and incentives, it cannot be said that Hutong residents' collective norm-enforcement behavior is simply a process of rational efficiency maximization. Considerations of economic efficiency certainly play an important role in the enforcement of norm-based dispute resolutions, but the various elements of resident decisionmaking in this area are somewhat difficult to parse. In fact, residents may be status or prestige maximizers as much as wealth maximizers, and while wealth and prestige often overlap and feed into one another, they can also create conflicting

308 Id.

${ }^{309}$ Interview with Resident Group, Taiping Jie Hutong neighborhood, supra note 282; Interview with Resident Group, Qianmen Hutong neighborhood, supra note 307; Interviews with Residents, Hou Hai Hutong neighborhood, supra note 79.

${ }^{310}$ Clearly community social solidarity is crucial to the effective enforcement of norm-based dispute resolutions in Hutong communities. Robert Cooter has asserted that actual consensus, rather than mere majority, is the best foundation for social norms and their associated enforcement systems. Consensus more closely approximates individual consent and thus provides a more stable (and perhaps legitimate) foundation for normbased regimes. See Cooter, supra note 261, at 978-79. 
incentives. While a resident who wants to build a norm-violating structure in common courtyard space may conclude that the economic benefits of such a structure outweigh the economic costs, including the costs created by neighborly reprisals, the prospect of public shame, or loss of social status might still preclude construction.

Scholars examining several different cultural traditions have observed that, in many social and cultural contexts, a desire to maximize social status can trump considerations of material gain. ${ }^{311}$ Some scholars have hypothesized that the very creation of social norms is essentially rooted in a desire for social esteem and prestige. ${ }^{312}$ Even in the ostensibly money-driven environment of the modern American workplace, it has been shown that status among one's co-workers matters, individual efforts at status display are common, and many important elements of worker compensation are fundamentally non-pecuniary. ${ }^{313}$ Of course, it is possible to argue that shifts in social status create practical difficulties that are ultimately "monetized" in the overall economic efficiency calculus, but it is not obvious that this is the case. Indeed, it is easy to conceive of purely social, emotive, or normative incentives that, while fundamentally unmonetized, would drive Hutong resident behavior. As Mauss himself observed: "It is our good fortune that all is not yet couched in terms of purchase and sale. Things have values which

311 Mauss notes that, in many societies,

great surpluses, even by European standards, are amassed; they are expended often at pure loss with tremendous extravagance and without a trace of mercenariness [sic] ... Diverse economic activities-for example, the market-are impregnated with ritual and myth; they retain a ceremonial character, obligatory and efficacious; they have their own ritual and etiquette.

MAUSS, supra note 306, at 69-70 (internal citations omitted). Studies of so-called "shame cultures" from around the world reinforce this point. In such cultures, spanning Western antiquity, pre-Columbian North America and much of East Asia, ostensibly straightforward economic efficiency considerations often appear to be trumped by desires for status or prestige, even to the point of individual financial ruin. To cite one wellknown example, in the potlatch ceremonies of Native American tribes in the U.S. Northwest, tribal leaders compete for status by giving away wealth, often to the exhaustion of all their household goods. In one recorded incident, a chieftan apparently even gave his guests the roof-boards of his dwelling in order to avoid shame and social stigma. In such social systems, wealth is not accumulated but given away or publicly destroyed in an effort to enhance one's social status. For a comprehensive discussion of the potlatch ceremony and its function in establishing individual social status, see H.G. BARNETT, The NATURE AND FunCTION OF THE POTLATCH 44-49, 77-85, 112-22 (1968).

312 See McAdams, supra note 91, at 342-43.

313 See RoBERT H. FRANK, CHOOSING THE RIGHT POND: HUMAN BEHAVIOR AND THE QUEST FOR STATUS 38, 82, 99-102, 146-53 (1985). 
are emotional as well as material; indeed in some cases the values are entirely emotional. Our morality is not solely commercial." 314

Over 20 years ago, Robert Mnookin and Lewis Kornhauser coined the phrase "bargaining in the shadow of the law" to describe the impact of legal provisions on private bargaining in divorce cases. ${ }^{315}$ In the Hutong environment, and perhaps in intra-group disputes arising in any tight-knit social community, the more apt characterization is bargaining in the shadow of the community. The "community," broadly understood to encompass both the individuals that make up the group and the various norms and conventions that comprise group culture, forms the social backdrop before which all inter-neighbor negotiations take place. In both its abstract and corporeal elements, the community sets the normative baselines against which alternative resolutions are evaluated, dictates the substantive content of mediated resolutions (through community-elected non-legalistic public authorities), and provides a means of effectively enforcing norm-based resolutions of disputes. Residents do not only bargain in the shadow of potential costly reprisals from neighbors, but also within a more general system of internalized values, implied responsibilities, and status hierarchies that the community inculcates in its members. The community will, as expressed in shared social norms and traditions, is thus the lodestar of most dispute resolution efforts, and Hutong residents will sooner disregard both law and immediate economic considerations as they pursue their own interests against intransigent neighbors.

\section{A LOOK AHEAD: THE IMPLICATIONS OF LEGAL REFORM, URBAN DEVELOPMENT, AND SOCIAL CHANGE}

The rapid economic, legal, and social changes now roiling Chinese society have been examined and analyzed by countless authors from many diverse fields. Government efforts at promoting the related goals of economic development and legal reform have had an enormous impact on Chinese life since the Reform and Opening era officially began in the early 1980 s. Chinese society has also undergone enormous social change during this period, some of it unanticipated and perhaps unwelcome. As has been discussed, Hutong life is not immune to such general social trends, and its

314 MAUSS, supra note 306 , at 63.

315 See Robert H. Mnookin \& Lewis Kornhauser, Bargaining in the Shadow of the Law: The Case of Divorce, 88 YALE L.J. 950, 950 (1979). 
dispute resolution regimes have reflected broader societal changes in certain ways. ${ }^{316}$

Yet, all things considered, the basic methods of dispute resolution in Beijing Hutongs have remained remarkably stable over the last several decades. Many of our interviewees had lived in the same Hutong for more than 40 years, and these community elders reported little change in the basic institutions of dispute resolution and the community norms that animate them. ${ }^{317}$ Naturally, Residents' Committees have become less politicized since the Great Leap Forward and the Cultural Revolution, 318 technology has made the allocation of common water and electricity costs less contentious, ${ }^{319}$ economic liberalization has required that Residents' Committee members receive salaries, ${ }^{320}$ and urban development has led many young residents to move out of old neighborhoods and into apartment buildings after marriage. ${ }^{321}$ Yet, while traditional solutions must be adjusted to accommodate a rapidly evolving social environment, the basic features of today's Hutong dispute resolution regime would be recognizable to a resident from the 1950s (and perhaps from the turn of the century).

This is not to say that the Hutong dispute resolution regime is "good" or "fundamental" in some categorical way, but merely that it has proven durable. Some scholars have contended that social norms are internalized only where "private incentives for signaling align with a local public

316 See supra Part IV (discussing Residents' Committees' historical development and recent professionalization).

317 This sentiment was expressed by older members of the community in many of our interviews. Interviews with Residents, Hou Hai Hutong neighborhood, supra note 81; Interview with Resident Group, Qianmen Hutong neighborhood, supra note 303; Interview with Resident Group, Taiping Jie Hutong neighborhood, supra note 282. 22.

318 See Interview with Residents' Committee, Jianguomen Wai District, supra note

319 As mentioned earlier, electricity costs are calculated according to mechanical meters in each household and are thus straightforward. By contrast, water costs are paid in one lump sum for each courtyard, with each family contributing money in proportion to the number of its members. This system was explained explicitly in several interviews. Interviews with Residents, Hou Hai Hutong neighborhood, supra note 81; Interview with Resident Group, Qianmen Hutong neighborhood, supra note 303; Interview with Resident Group, Liu Li Chaing Hutong neighborhood, supra note 240.

320 Interview with Residents' Committee, Jianguomen Wai District, supra note 22.

321 This phenomenon was also corroborated in several interviews, mostly by older residents who lamented the trend and feared its implications for the future of the community. Interviews with Residents, Hou Hai Hutong neighborhood, supra note 81; Interview with Resident Group, Qianmen Hutong neighborhood, supra note 303; Interview with Resident Group, Taiping Jie Hutong neighborhood, supra note 282. 
good." 322 Under this view, time-tested community norms reflect the efficient evolution of local social structures; the norms that emerge from longstanding social practice are the "good" ones, and they should be upheld and applied as such. ${ }^{323}$ Others have observed that the dynamics of established social communities are not uniformly healthy, suggesting that group-specific norms must be subject to constant reexamination. As Robert Putnam noted, social capital, so central to norm-based social systems, "can be directed toward malevolent, antisocial purposes, just like any other form of capital." 324 Norms, in short, can be destructive as well as constructive. Their mere existence should not be taken as proof of their value.

The dispute resolution regime examined here is certainly not immune from the implications of this debate. While the traditional norm-based system has certainly proven effective in maintaining a certain amount of social order and community solidarity, it also has evolved largely in response to a corrupt legal and political order. While surely existing largely outside that order, the extent to which its underlying assumptions and practices have been molded by a corrupt officialdom remains an open question. In response to a legal system plagued by corruption, Hutong residents have built an extra-legal (one might say anti-legal) dispute resolution regime where personal relationships, informal gift exchange, and individual self-help - the very stuff of corruption and patronage in more official contexts-are of central importance. How will the durability of this system, and others like it, affect government attempts to construct a more efficient, rationalized, rule-based legal order? In legal institution-building, the barriers created by official corruption may not lie merely in the policies and practices of government, but in the pragmatic, norm-based, extralegal systems that rational people establish to protect their own communities and provide for their own welfare in the face of systemic inadequacies. This difficulty is exacerbated when these norm-based local traditions are of long standing.

It is widely accepted that law itself can perform a powerful expressive function, reinforcing certain norms and discouraging others. ${ }^{325}$ As such,

322 Robert D. Cooter, Structural Adjudication and the New Law Merchant: A Model of Decentralized Law, 14 INT'L REV. L. \& ECON. 215, 224 (1994); see also Robert D. Cooter, Decentralized Law for a Complex Economy: The Structural Approach to Adjudicating the New Law Merchant, 144 U. PA. L. REV. 1643, 1676 (1996).

323 See Cooter, Structural Adjudication, supra note 322, at 224.

324 PUTNAM, supra note 219, at 21-22.

325 Cass Sunstein has produced the most general and influential treatments of this topic, examining the expressive impact of legal rules in undermining destructive social norms such as smoking and unprotected sex. See Sunstein, supra note 91, at 2035; 
current Chinese efforts at legal reform will undoubtedly have an impact on Hutong social norms, but the ultimate implications of this fact are hard to ascertain ex ante. ${ }^{326}$ Ideally, one would hope for an "alignment of law with morality," 327 or a "coincidence between the legal prescription and community opinion," 328 whereby the enforcement of laws and norms, through both public and private channels, are complementary and mutually reinforcing.

Yet, even if law is ultimately successful in influencing community norms, the results can be destructive. Richard $\mathrm{H}$. Pildes has noted what he calls "law's norm-destroying capacity"-the ability of legal rules to undermine social norms that are themselves instrumental to the effective application of the law. ${ }^{329}$ Pildes asserts that state action can destroy the social capital that undergirds social norms by removing the "structural conditions" for social capital formation (as when it destroys neighborhoods and organic social networks through urban renewal programs), or by precluding traditional social practices and "distinctions" (as when attempts to "rationalize" legal practice preclude the operation of informal reciprocity norms). ${ }^{330}$ Additionally, even when government earnestly tries to incorporate social norms into its legal institutions, associated enforcement mechanisms often lose the flexibility and customization that made preexisting norm-based systems viable. In other words, law is simply too blunt and rigid a tool to enforce certain norms without damaging the social fabric of the community. .31

These are all considerations that the Chinese government would do well to ponder. Its recent efforts to institute comprehensive legal reforms and pursue urban development projects (some of which involve Hutong demolition) could be fraught with difficulty, both for the residential communities affected and for the government's own modernization programs. In the worst case, new laws contrary to long-standing social norms

Sunstein, supra note 9, at 945-46; see also McAdams, supra note 91, at 342-43 (noting that law can expressively reinforce or undermine social norms).

326 See Sunstein, supra note 9, at 907-08. “[G]overnment deserves to have, and in any case inevitably does have, a large role in norm management. [N]orm, management is an important strategy for accomplishing the objectives of law, whatever those objectives may be." Id.

327 Cooter, supra note 261, at 979.

328 Elizabeth S. Scott, The Legal Construction of Norms: Social Norms and the Legal Regulation of Marriage, 86 VA. L. REV. 1901, 1969 (2000).

329 Pildes, supra note 260, at 2057.

$330 \mathrm{Id}$. at 2077.

$331 \mathrm{Id}$. 
could foment a governance crisis for a regime whose authority and legitimacy have been in flux since 1979.332 At the very least, new laws that disregard established norms may destroy social capital, preclude the use of more efficient informal dispute resolution mechanisms, and damage the social makeup of Hutong communities.

Government demolition of Hutong neighborhoods and relocation of residents to new apartment high-rises ${ }^{333}$ could have similar effects, destroying useful norm-based systems and socially alienating former residents. All of our older interviewees expressed anxiety at the prospect of being moved to a new location. In addition to the understandable sentimental ties they had to their current homes, they also feared the absence of human contact and the lack of a social support network they might face in high-rise apartment buildings. Thinking on the most practical of levels, one resident asserted that she did not want to have to use stairs or elevators at her advanced age, and she wondered aloud about the isolation she might face: "What if I am sick? What if I fall down? Who will know I am in trouble? Who will help me?"334 Others simply stated that they would miss their neighbors, their interactions with local children and their weekly mah jong games. ${ }^{335}$ These kinds of considerations may or may not be appropriate to legal reform or urban policy decisions, but the social costs of urban development, whether reckoned in terms of social capital or normative principles, are real. ${ }^{336}$

As for the ultimate fate of the current Hutong dispute resolution regime, the future course of Chinese legal reform and urban development policy will have a crucial impact. To the extent that Chinese citizens become richer and better educated in the years to come (which seems almost certain to occur), some of the purely monetary incentives to use informal norms rather than formal law will soften. If more and more Chinese can afford recourse to

332 Minxin Pei has recently asserted that the Chinese government is already undergoing a "Governance Crisis," though he places the fundamental causes within the Chinese political system and relations between central government authorities in Beijing and regional administrative structures. See Minxin Pei, China's Governance Crisis, FOREIGN AFFAIRS, Sept.--Oct. 2002, at 96.

333 See supra Part II (discussing the history of Hutongs and recent urban development policies).

334 Interview with Resident Group, Taiping Jie Hutong neighborhood, supra note 282.

335 Interview with Resident Group, Qianmen Hutong neighborhood, supra note 303.

336 See JACOBS, supra note 54, at 3-25 (discussing the most famous critique of modern urban development programs and their adverse effects on city social environments). 
formal legal channels, it is likely that they will make greater use of formal law in their disputes. Similarly, to the extent that ongoing Chinese legal reform programs can deliver clear, coherent, and normatively acceptable new laws - and, perhaps most crucially, to the extent that the government can control official corruption and ensure the faithful enforcement of legal rules-the uncertainties surrounding the content and application of formal legal system might be alleviated. This too would encourage increased use of formal law by Chinese citizens.

Additionally, fundamental demographic and structural changes in Hutong communities continue as these words are written. Residents reported that younger residents often moved out of Hutong communities when they reached adulthood, preferring the modern amenities and greater privacy of newer apartment buildings to the older, more crowded courtyards where they grew up. ${ }^{337}$ Residents also reported that, as a result, their communities are getting older in general, consisting largely of parents and grandparents whose children have grown up and moved out. ${ }^{338}$ Young people are becoming more mobile, educated, and affluent than their parents in China today, and this will continue to have an adverse effect on the social cohesion of more traditional communities, as it has in Western countries. Even Residents' Committee mediators themselves - the most immediate and visible stewards of the old Hutong folkways-are becoming increasingly educated and professionalized. ${ }^{339}$

One particularly interesting new trend is the recent influx of foreign residents in Hutong communities. Attracted by the history and charm of the Hutong areas themselves, a few foreigners have bought residences in Beijing's more famous Hutong districts (especially the scenic Houhai neighborhood), often with an eye towards refurbishing and modernizing them. ${ }^{340}$ In fact, in one Shanghai Hutong neighborhood, a foreign resident was recently elected to the Residents' Committee, something apparently unprecedented in Chinese history. Insofar as such demographic shifts impact the social fabric of Hutong communities (as they must), many of the purely social foundations of the traditional dispute resolution system may change in unforeseen ways.

${ }^{337}$ Interviews with Residents, Hou Hai Hutong neighborhood, supra note 79; Interview with Resident Group, Taiping Jie Hutong neighborhood, supra note 282; Interview with Resident Group, Liu Li Chang Hutong neighborhood, supra note 240.

338 See supra note 337.

339 See supra Part IV (discussing the historical development of Residents' Committees).

340 Interviews with Residents, Hou Hai Hutong neighborhood, supra note 79. 
Of course, Hutong demolition will have the most direct and potentially catastrophic impact on traditional dispute resolution systems. This is exactly the kind of change in "structural conditions" that Pildes claims can destroy traditional norm-based systems. ${ }^{341}$ Of course, one must carefully distinguish between the physical Hutong neighborhoods themselves and the distinctive dispute resolution regime that has developed within them. It is conceivable that existing dispute resolution techniques may simply be transplanted to new residential environments as urban development projects proceed.

Yet this appears a highly dubious proposition. At the very least, the greater social and physical distance between residents in new apartment buildings threaten to undermine the mediation and enforcement of normbased dispute resolutions, as the transactions costs of communicating with neighbors, gathering information on their activities, and applying informal reprisals against norm-violators - the fundamental components of a normbased dispute resolution system—will be higher. ${ }^{342}$ To invoke Ellickson's construct of the "close-knit" group once more: Residents will have a smaller "supply of information on past and present internal events" and reduced "prospects for the application of power against one another." 343 In this respect, the physical design of new apartment buildings will be a key factor in determining the transferability of Hutong ways of life- and all of the rich social capital they create- to new residential environments. Buildings that are physically conducive to neighborly interaction, communication, and

341 Pildes, supra note 260, at 2077.

342 One should not underestimate the fundamental changes in social dynamics that can result from a shift to modern apartment life. The physical smallness of a Hutong household means that Hutong residents must venture out into common courtyard areas several times each day (in fact, most residents spend the majority of their leisure time in shared courtyard areas), while individuals in larger multi-room apartments can stay indoors for long stretches of time, avoiding their neighbors altogether. The physical separation and self-sufficiency of apartment kitchens and bathroom facilities also reduces opportunities for contact and communication. In Hutong communities, toilets are shared by the residents of one courtyard, and cooking is often done in common areas. In apartment buildings, residents also have a separate entranceway to their own dwelling whereas in Hutongs one common courtyard entryway is usually shared by multiple households, creating unavoidable contact between neighbors during the course of a normal day. The mere presence of a heavy door that can be locked and thicker walls that prevent household noise from being widely heard by neighbors is also critical in differentiating the modern apartment environment. By contrast, noise travels easily through Hutong courtyards, as attested to by the prevalence of noise disputes in Residents Committees' mediation activities.

343 ELLICKSON, supra note 1 , at 181 . 
bonding will be much more hospitable to social capital-intensive practices. ${ }^{344}$ If nothing else, it should be recognized that Hutongs are rich in social capital-just as they are undeniably poor in physical capital-and as such their complete demolition might be a mistake if they are replaced by poorlydesigned buildings.

All of these considerations notwithstanding, it would be premature to mourn the death of this distinctive three-tiered dispute resolution regime just yet. For one, the system is deeply rooted in the culture of Chinese urban life. ${ }^{345}$ Traditions must adapt as changing times dictate, but this particular regime has endured many transitions: from imperial rule at the turn of the century, to fractured republican government in the pre-war decades, to invasion and occupation by foreign armies in the $1930 \mathrm{~s}$ and $40 \mathrm{~s}$, to Communist revolution and totalitarianism, and finally to the current reform and opening period. The dislocations of marketization may in time do what war and political revolution could not, but this remains an open question. Indeed, aggressive economic reform programs have fostered explosive economic growth and fundamental societal change for more than 20 years already, and the Hutong dispute resolution system has endured. Additionally, the Hutongs themselves are not disappearing completely, as many of the older Hutong neighborhoods are now being preserved as "cultural protection zones." 346

In sum, the ultimate fate of the Hutong dispute resolution regime examined here is far from clear. Government efforts at legal reform, economic growth, and urban modernization all pose potential threats to its survival, as do more general social and demographic shifts already underway. Urban development may destroy the social capital and structural conditions necessary for regime functioning as Hutong neighborhoods are demolished. New legal institutions may remove some of the cost-based incentives to use the traditional norm-based regime, though this is not likely to have a dramatic effect in the short-term. To the extent that legal reform efforts cultivate a greater sense of legalism and rights-consciousness in the population, this may have deep implications for extralegal dispute resolution regimes of all types, especially if new laws actually oppose the use of certain traditional norms. Yet, even if realized, these possibilities imply complex social and cultural transitions that take a long time to develop.

344 The importance of architecture in shaping the social realities of residential communities has been wonderfully explored by Neal Katyal. Neal Katyal, Architecture as Crime Control, 111 YALE L.J. 1039, 1041-44 (2002).

345 See supra Part II (discussing Hutong culture and historical development).

346 See Adhikari, supra note 14; Will Beijing's Hutongs Vanish?, supra note 14. 
Yet these trends cut both ways. Hutong dispute resolution methods are time-tested, rooted in hundreds of years of cultural tradition and accumulated social practice. More importantly, they seem to be effective in maintaining social order within Hutong neighborhoods, and by definition, they seem to embody the methods most normatively acceptable to members of these communities. As such, legal reformers ignore Hutong norms at their peril. At the least, laws ill-fitted to existing norms can preclude the functioning of efficient norm-based dispute resolution regimes and destroy social capital in the process. At the worst, such laws could actually discredit the legal system more generally, galvanize popular support for countervailing norms, and deepen social tendencies toward extralegality.

Conversely, new laws that dovetail with existing social norms will likely benefit from increased normative legitimacy among the populace and fewer problems surrounding their practical application. Ideally, new laws and legal institutions could harness efficient norm-based systems and incorporate both their substantive content and their institutional apparatus into new legal institutions. Legal reformers seeking to establish a "rule of law" 347 in China will confront this coincidence of opportunity and peril in all areas of Chinese law where preexisting norm-based regimes exist (i.e., almost everywhere). The Hutong regime discussed here provides but one particularly colorful and informative example.

\section{SUMMARY}

This Article corroborates much of the prior scholarship that emphasizes the important role of extralegal norms in guiding dispute resolution among members of distinct communities. Like the "close-knit" groups examined in other studies, Hutong residents appear fundamentally predisposed to resolve inter-neighbor disputes extra-legally through recourse to dispute resolution mechanisms based entirely in informal community social norms. Hutong residents regard formal legal institutions as too costly in terms of time, money, and social capital, and too unpredictable and opaque to be an efficient means of dispute resolution in most cases. Recourse to formal law is reserved for instances where the monetary value of the amounts in dispute far exceed the costs of going to court, and where existing social relationships-and hence the prospect of expected future interactions between disputants-

347 This incredibly broad and politically loaded term admits many definitions and interpretations. Most any of the conventional ones will suffice for the purposes of our discussion here. 
are either extinguished or de-valued (i.e., where disputants are at "end game").

While this project confirms some of the basic conclusions of prior studies, it also raises a few new issues related to dispute resolution within the context of a developing or transitional legal system, hints at institutional possibilities largely ignored in prior studies, and challenges some of the implicit or explicit assumptions that have guided prior treatments of normbased dispute resolution systems.

The opacity and uncertainty-as opposed to mere economic costassociated with formal legal institutions is something not emphasized in the prior literature on the subject, and indeed may be most relevant to dispute resolution regimes in nascent or institutionally deficient legal systems. As such, it may be an important factor in shaping dispute resolution regimes in developing countries generally. Additionally, while residents' preferences for extra-legal, norm-based solutions to disputes appear universal, our research hints at the variety of institutional channels through which they might pursue such solutions. Hutong residents actually use a three-tiered, scalable dispute resolution regime that allows them to choose from among a range of dispute resolution mechanisms, each implying a different level of legalism, cost, flexibility, social disruption, and access to state power. Residents can choose the systemic tier whose institutions best suit the exigencies of their particular dispute, and they can switch between tiers and "re-scale" as their needs dictate.

The first tier is the private, neighbor-to-neighbor bargaining, which combines the highest degree of flexibility with the lowest levels of cost, legalism, and access to state power. This is the kind of private bargaining envisioned by Ronald Coase and emphasized by most of the literature on norm-based dispute resolution regimes. The third tier is comprised of formal legal dispute resolution mechanisms, which encompass the official legal system and all of its institutional trappings. This third tier implies the highest economic costs, the least flexibility, and the greatest social disruption, but it provides the greatest access to the coercive powers of the state.

The second tier is the most analytically interesting, made up of "nonlegalistic public authorities" such as the Residents' Committee and the Neighborhood Police. These institutional actors are specialized mediation "experts" sanctioned and compensated by the government, yet they lack coercive powers and are distinctly extra-legal local in both the sources and application of their authority. They are elected by the community, they apply community norms rather than formal legal rules to the disputes brought before them, and they rely on informal social sanctions and direct physical reprisals by other community members for the enforcement of their mediated 
resolutions. In this way, Hutong residents benefit from the speed, costeffectiveness, and flexibility of more "pure" norm-based private negotiations while benefiting from the intervention of mediation "experts" who can provide added predictability and public legitimacy to dispute resolutions, alleviate problems of bilateral monopoly in intra-neighbor negotiations, and ensure that disputes are contained and resolved in socially constructive ways.

Unlike professional ADR mediators summoned to handle a single specific dispute or arbitration, Residents' Committee mediators are repeat players with so-called general jurisdiction, able to create a richer, more consistent, and more comprehensive norm-based regime, complete with predetermined principles, exceptions, and unofficial common-law-style precedents for various dispute types. Expert-mediated resolutions are in turn enforced by individual members of the community, who impose economic and social costs on intransigent neighbors. Here, residents are not just minimizing traditionally understood transaction costs, but are also maximizing social status and social capital and seeking the esteem of their neighbors, even if it proves to be an entirely non-pecuniary benefit. This dynamic does not merely implicate the reputation-as-economic-asset concept so prevalent in the literature concerning the role of norms in business communities; it includes situations where social status may be sought for its own sake, even at the expense of economic efficiency. Residents also exhibit an internalized sense of duty to uphold community norms, rooted in both the intimate social nature of Hutong life and fundamental notions of social duty and reciprocity.

Thus, Hutong residents can be seen as "bargaining in the shadow of the community" in the most comprehensive sense. Shared community norms provide the preferred basis for dispute resolution, and they animate the activities of the non-legalistic public authorities charged with mediating disputes and maintaining community harmony. Private informal sanctioning by members of the community also provide the primary means of enforcing norm-based resolutions, along with deep notions of social status and communal obligations. While the norms that structure community life are private and extra-legal in a very real sense, our research indicates that semilegalistic, public institutions can have an important role to play in their maintenance and productive application. 
